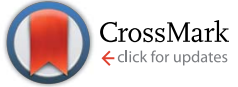

Cite this: J. Mater. Chem. A, 2016, 4, 17180

Received 15th July 2016

Accepted 7th October 2016

DOI: $10.1039 / c 6 t a 05980 e$

www.rsc.org/MaterialsA

\section{Variation in surface energy and reduction drive of a metal oxide lithium-ion anode with stoichiometry: a DFT study of lithium titanate spinel surfaces $\uparrow$}

\author{
Benjamin J. Morgan, ${ }^{\star a}$ Javier Carrasco*b and Gilberto Teobaldi*c
}

$\mathrm{Li}_{4} \mathrm{Ti}_{5} \mathrm{O}_{12}$ is a "zero-strain" lithium-ion anode material that shows excellent stability over repeated lithium insertion-extraction cycles. Although lithium (de)intercalation in the bulk material has been well characterised, our understanding of surface atomic-scale-structure and the relationship with electrochemical behaviour is incomplete. To address this, we have modelled the $\mathrm{Li}_{4} \mathrm{Ti}_{5} \mathrm{O}_{12}(111), \mathrm{Li}_{7} \mathrm{Ti}_{5} \mathrm{O}_{12}$ (111) and $\alpha-\mathrm{Li}_{2} \mathrm{TiO}_{3}$ (100), (110), and (111) surfaces using Hubbard-corrected density-functional theory $(G G A+U)$, screening more than 600 stoichiometric $\mathrm{Li}_{4} \mathrm{Ti}_{5} \mathrm{O}_{12}$ and $\mathrm{Li}_{7} \mathrm{Ti}_{5} \mathrm{O}_{12}$ (111) surfaces. For $\mathrm{Li}_{4} \mathrm{Ti}_{5} \mathrm{O}_{12}$ and $\mathrm{Li}_{7} \mathrm{Ti}_{5} \mathrm{O}_{12}$ we find $\mathrm{Li}$-terminated surfaces are more stable than mixed Li/Ti-terminated surfaces, which typically reconstruct. For $\alpha-\mathrm{Li}_{2} \mathrm{TiO}_{3}$, the (100) surface energy is significantly lower than for the (110) and (111) surfaces, and is competitive with the pristine $\mathrm{Li}_{7} \mathrm{Ti}_{5} \mathrm{O}_{12}$ (111) surface. Using these stoichiometric surfaces as reference, we also model variation in $\mathrm{Li}$ surface coverage as a function of lithium chemical potential. For $\mathrm{Li}_{4} \mathrm{Ti}_{5} \mathrm{O}_{12}$, the stoichiometric surface is most stable across the full chemical potential range of thermodynamic stability, whereas for $\mathrm{Li}_{7} \mathrm{Ti}_{5} \mathrm{O}_{12}$, $\mathrm{Li}$ deficient surfaces are stabilised at low $\mathrm{Li}$ chemical potentials. The highest occupied electronic state for $\mathrm{Li}_{7} \mathrm{Ti}_{5} \mathrm{O}_{12}$ (111) is 2.56 $\mathrm{eV}$ below the vacuum energy. This is $0.3 \mathrm{eV}$ smaller than the work function for metallic lithium, indicating an extreme thermodynamic drive for reduction. In contrast, the highest occupied state for the $\alpha-\mathrm{Li}_{2} \mathrm{TiO}_{3}$ (100) surface is $4.71 \mathrm{eV}$ below the vacuum level, indicating a substantially lower reduction drive. This result demonstrates how stoichiometry can strongly affect the thermodynamic drive for reduction at metal-oxide-electrode surfaces. In this context, we conclude by discussing the design of highly-reducible metal-oxide electrode coatings, with the potential for controlled solid-electrolyteinterphase formation via equilibrium chemistry, by electrode wetting in the absence of any applied bias.

\section{Introduction}

The global transition from fossil fuels to renewable low-carbon primary energy sources is, at present, hindered by the need for secondary energy storage technologies that can operate reliably and cheaply. Lithium-ion batteries are widely used for secondary energy storage in personal electronics, and increasingly in hybrid electric vehicles, but scaling commercial technologies up to grid-scale capacities presents a challenge. Conventional Li-ion batteries use graphite anodes, which are low cost and have excellent lithium-intercalation kinetics. The low intercalation potential of graphite with respect to $\mathrm{Li} / \mathrm{Li}^{+}$ means rapid charging causes metallic $\mathrm{Li}$ to plate at the

${ }^{a}$ Department of Chemistry, The University of Bath, Claverton Down, Bath, BA2 7AY, UK ${ }^{b}$ CIC Energigune, Albert Einstein 48, 01510 Miñano, Álava, Spain

'Stephenson Institute for Renewable Energy, Department of Chemistry, The University of Liverpool, Liverpool, L69 3BX, UK. E-mail: g.teobaldi@liverpool.ac.uk

$\dagger$ Electronic supplementary information (ESI) available. See DOI: 10.1039/c6ta05980e electrode-electrolyte interface. ${ }^{\mathbf{1}}$ Inhomogeneous Li plating can precipitate $\mathrm{Li}$ dendrite growth, eventually causing the cell to short-circuit. Conventional Li-ion batteries use liquid or polymer organic electrolytes, and the rapid release of energy during a short-circuit can initiate electrolyte combustion, presenting a serious safety concern. In addition, in graphite the intercalation and extraction of lithium produces large volume changes. Repeated charge-discharge cycles can cause the electrode to crack, potentially breaking contact between electrode particles and causing irreversible capacity loss. This manifests as a gradual degradation of battery performance and contributes to limited battery lifetimes, increasing the lifetime costs of gridscale storage.

One strategy to address these problems is to replace graphite anodes with a material less prone to lithium plating or cracking. A promising alternative is $\mathrm{Li}_{4} \mathrm{Ti}_{5} \mathrm{O}_{12}$, which readily intercalates three lithium ions per formula unit at a voltage of $1.56 \mathrm{~V}$ versus $\mathrm{Li} / \mathrm{Li}^{+}$to form $\mathrm{Li}_{7} \mathrm{Ti}_{5} \mathrm{O}_{12} \cdot{ }^{2} \mathrm{Li}_{4} \mathrm{Ti}_{5} \mathrm{O}_{12}$ offers high $\mathrm{Li}$-insertion and extraction rates, and importantly shows excellent stability over 
repeated cycles, attributed to two properties. First, $\mathrm{Li}_{4} \mathrm{Ti}_{5} \mathrm{O}_{12}$ is a "zero-strain" intercalation compound, with $\mathrm{Li}$ intercalation producing lattice parameter changes smaller than $0.1 \%{ }^{3}$ Second, the relatively high potential for lithium intercalation of $1.56 \mathrm{~V}$ limits the formation of dendritic $\mathrm{Li}$, which mitigates both the degradation of cell performance over repeated charge/ discharge cycles and the risk of catastrophic short-circuiting.

The properties of bulk $\mathrm{Li}_{4} \mathrm{Ti}_{5} \mathrm{O}_{12}$ have been studied in a number of previous works. ${ }^{4-9}$ The operational characteristics of an electrode, however, depend not only on bulk properties, but also on the electrode-electrolyte interface. During $\mathrm{Li}^{+}$ insertion and extraction, lithium ions move across this interface and through the electrode near-surface region. Local diffusion barriers, which may differ from bulk values, determine insertion and extraction kinetics and associated overpotentials. ${ }^{\mathbf{1 0}}$ Electrochemical side-reactions at the electrode surface, such as continuous reduction of the electrolyte to form a solid-electrolyte interphase (SEI), may also degrade cell performance over repeated cycles. The thermodynamic driving force for reductive surface reactions, involving electron transfer from the electrode to the electrolyte, depends on the binding energy for electrons at the surface (relative to a fixed reference, such as the vacuum energy). Surface electron binding energies may deviate from bulk values, due to band bending, and electrochemical reactivity and stability of electrode surfaces therefore depend on their composition and atomic geometry.

A rational development of improved energy storage solutions requires understanding the relationships between electrode surface composition, geometry, and resulting electrochemical properties (SEI formation and evolution included). The challenge of experimentally resolving atomicscale surface structure and electronic properties makes explicit computational modelling a powerful complementary approach for relating electrode surface chemistry to electrochemical performance. Here we focus on the case of $\mathrm{Li}_{4} \mathrm{Ti}_{5} \mathrm{O}_{12}$, which shows particularly interesting behaviour. In 2012, Kitta et $a{ }^{11}{ }^{11}$ studied the evolution of the atomic structure and electrochemical properties of a $\mathrm{Li}_{4} \mathrm{Ti}_{5} \mathrm{O}_{12}$ (111) surface during initial lithium insertion and extraction cycles, using a combination of atomic force microscopy (AFM), transmission electron microscopy (TEM), and electron energy loss spectroscopy (EELS). Starting from a pristine atomically flat (111) surface, the first lithium insertion-extraction cycle produced an irreversible structural change, accompanied by a $10 \mathrm{~nm}$ increase in surface roughness. After this first cycle, the charge transfer resistance of the electrode/electrolyte interface fell by half, then remained constant for the following charge-discharge cycles. By analysing TEM data these authors identified an epitaxially-matched $\alpha-\mathrm{Li}_{2} \mathrm{TiO}_{3}$ surface-layer phase formed during the first insertion/extraction cycle.

An epitaxially matched surface-layer phase, such as $\alpha-\mathrm{Li}_{2} \mathrm{TiO}_{3}$ on $\mathrm{Li}_{4} \mathrm{Ti}_{5} \mathrm{O}_{12}$, may be considered as a solid-electrolyte interphase component. Because the electrochemical performance of an electrode depends on the surface composition, the observations of Kitta et al. suggest an intriguing strategy for tailoring electrode surface properties. Targetted in situ growth of specific surface-layer phases may lead to enhanced electrode rate capabilities and stability, and correspondingly increased operational lifetimes. In this respect the $\mathrm{Li}_{4} \mathrm{Ti}_{5} \mathrm{O}_{12} / \mathrm{Li}_{7} \mathrm{Ti}_{5} \mathrm{O}_{12} / \alpha$ $\mathrm{Li}_{2} \mathrm{TiO}_{3}$ system represents an exemplar case for studying the role of surface composition on electrochemical characteristics, as well as being directly relevant to the use of $\mathrm{Li}_{4} \mathrm{Ti}_{5} \mathrm{O}_{12}$ as a high-stability Li-electrode.

To understand how a surface-layer $\alpha-\mathrm{Li}_{2} \mathrm{TiO}_{3}$ phase affects the electrochemical properties of the $\mathrm{Li}_{4} \mathrm{Ti}_{5} \mathrm{O}_{12}$ anode, there is a timely need for an atomically resolved structural description of the competing surfaces and a comparison of their electronic properties. These aspects are challenging to access experimentally: in the study of Kitta et al. the structural data lack the atomic resolution necessary to identify competing surface morphologies, while electronic properties, such as the electrostatic potential across the electrode-electrolyte interface region, are not accessible. Density functional theory (DFT) is a useful tool in both these regards, because it provides a direct description of atomic scale geometries and of electronic structure, and for this reason DFT is a well established approach for studying simple surfaces. ${ }^{\mathbf{1 2}}$

In the case of $\mathrm{Li}_{x} \mathrm{Ti}_{5} \mathrm{O}_{12}$ surfaces, computational modelling remains challenging. The presence of non-equivalent crystallographic cuts through the $\mathrm{Li}_{x} \mathrm{Ti}_{5} \mathrm{O}_{12}$ unit cell means competing surface planes must be considered. Furthermore, to draw reliable conclusions, one must consider the size of the configurational space with regard to different arrangements of surface atoms, which can be computationally restrictive for materials with low unit-cell symmetries, such as $\mathrm{Li}_{x} \mathrm{Ti}_{5} \mathrm{O}_{12}$. Previous computational studies of $\mathrm{Li}_{x} \mathrm{Ti}_{5} \mathrm{O}_{12}$ surfaces have relied on various simplifying approximations. Gao et al. previously used density-functional theory (DFT) to investigate competing $\mathrm{Li}_{4} \mathrm{Ti}_{5} \mathrm{O}_{12}$ (111) surface terminations. ${ }^{\mathbf{1 3 , 1 4}}$ The complex $\mathrm{Li}_{4} \mathrm{Ti}_{5} \mathrm{O}_{12}$ cell was approximated using the simpler $\mathrm{LiTi}_{2} \mathrm{O}_{4}$ spinel structure, and possible rearrangements of atoms in the surface layer were not considered. Weber et al. have also used DFT to calculate surface energies of the (100), (110), and (111) $\mathrm{Li}_{4} \mathrm{Ti}_{5} \mathrm{O}_{12}$ and $\mathrm{Li}_{7} \mathrm{Ti}_{5} \mathrm{O}_{12}$ surfaces. ${ }^{15}$ Only a single geometry was modelled for each surface, and it is not known, therefore, whether these surface energies represent thermodynamically favoured low energy surfaces, or whether more stable surfaces with different surface planes or alternate surface atom arrangements exist. The primary objective of this work is to provide an extensive energy screening of $\mathrm{Li}_{4} \mathrm{Ti}_{5} \mathrm{O}_{12}, \mathrm{Li}_{7} \mathrm{Ti}_{5} \mathrm{O}_{12}$, and $\alpha-\mathrm{Li}_{2} \mathrm{TiO}_{3}$ surfaces.

To this end, we report DFT calculations of the (111) $\mathrm{Li}_{4} \mathrm{Ti}_{5} \mathrm{O}_{12}$ and $\mathrm{Li}_{7} \mathrm{Ti}_{5} \mathrm{O}_{12}$ surfaces, and the (100), (110), and (111) surfaces of $\alpha-\mathrm{Li}_{2} \mathrm{TiO}_{3}$, considering a total of more than 600 surface structures. For the $\mathrm{Li}_{x} \mathrm{Ti}_{5} \mathrm{O}_{12}$ surfaces we consider competing surface terminations along the (111)-oriented unit cell, and perform a search over different configurations and stoichiometries of under-coordinated cations at each exposed surface. For $\alpha-\mathrm{Li}_{2} \mathrm{TiO}_{3}$ the significant surface roughness observed by Kitta et al. ${ }^{11}$ for the (111)-grown surface means other crystallographic surfaces might be present in the final as-grown surface morphology, and we therefore compare energies of three lowindex surfaces.

A complete theoretical description of $\mathrm{Li}_{x} \mathrm{Ti}_{5} \mathrm{O}_{12}$ surfaces under all accessible experimental conditions requires 
considering a comprehensive set of surface stoichiometries, each of which may become favoured at component atom chemical potentials. A computational study of all possible surface stoichiometries is impractical: an infinite number of surface configurations may be constructed. To ensure our study is computationally tractable, we first restrict our attention to stoichiometric surface models. For the stoichiometric surface models with lowest energy we then consider adding or removing surface atoms, to understand how the surface structure varies with chemical conditions.

We find that $\mathrm{Li}_{x} \mathrm{Ti}_{5} \mathrm{O}_{12}$ (111) surfaces with pure lithium terminations are more stable than surfaces with mixed lithiumtitanium terminations, which tend to reconstruct. For $\alpha-\mathrm{Li}_{2} \mathrm{TiO}_{3}$ the (100) surface energy is significantly lower than the (110) and (111) surface energies. This indicates that planar (111)-terminated surfaces are unstable with respect to highly-facetted (100)-terminated surfaces. This preference for surface facetting may contribute to the surface roughening observed by Kitta et al. during formation of the $\alpha-\mathrm{Li}_{2} \mathrm{TiO}_{3}$ surface phase in $\mathrm{Li}_{x^{-}}$ $\mathrm{Ti}_{5} \mathrm{O}_{12}{ }^{11}$ For $\mathrm{Li}_{4} \mathrm{Ti}_{5} \mathrm{O}_{12}$ (111), under all conditions where $\mathrm{Li}_{4} \mathrm{Ti}_{5} \mathrm{O}_{12}$ is thermodynamically stable, stoichiometric Literminated surfaces are predicted to be stable versus addition or removal of surface lithium. For $\mathrm{Li}_{7} \mathrm{Ti}_{5} \mathrm{O}_{12}$ (111) however, Lideficient surfaces may be stabilised within a narrow range of low lithium chemical potentials, before lithium deintercalation from the bulk to form $\mathrm{Li}_{4} \mathrm{Ti}_{5} \mathrm{O}_{12}$.

By comparing electronic structures and electron binding energies of the $\mathrm{Li}_{x} \mathrm{Ti}_{5} \mathrm{O}_{12}$ (111) and $\alpha-\mathrm{Li}_{2} \mathrm{TiO}_{3}$ (100) surfaces, we have investigated the thermodynamic driving force for reductive reactions at the $\alpha-\mathrm{Li}_{2} \mathrm{TiO}_{3}$ surface-layer phase compared to pristine $\mathrm{Li}_{x} \mathrm{Ti}_{5} \mathrm{O}_{12}$. We find electrons are bound more strongly at the (100) $\alpha-\mathrm{Li}_{2} \mathrm{TiO}_{3}$ surface than at the (111) $\mathrm{Li}_{7} \mathrm{Ti}_{5} \mathrm{O}_{12}$ surface, by $2.1 \mathrm{eV} . \alpha-\mathrm{Li}_{2} \mathrm{TiO}_{3}(100)$ is therefore expected to be much less reductively reactive than $\mathrm{Li}_{7} \mathrm{Ti}_{5} \mathrm{O}_{12}$ (111). For $\mathrm{Li}_{7} \mathrm{Ti}_{5} \mathrm{O}_{12}$ (111) the energy difference between the highest occupied state and the vacuum energy is only $2.49 \mathrm{eV} .^{16}$ This is even smaller than the work function of metallic lithium of $\sim 2.9 \mathrm{eV},{ }^{17,18}$ which is experimentally observed to reduce electrolytes even in the absence of an applied bias. Zero-bias SEI formation has been observed in the lithium-ion cathode $\mathrm{LiMn}_{2} \mathrm{O}_{4}$ for surface facets with a large reduction drive, after electrolyte wetting. ${ }^{\mathbf{1 9 , 2 0}}$ The development of materials or coatings with highly reducing surface facets, which may allow controlled zero-bias SEI formation, is an interesting and possibly quite general design strategy for future high stability electrodes. For this strategy to be rationally explored, it is necessary to link the composition and structure of an electrode surface to the relevant redox chemistry thermodynamics, which we provide here for the competing phases and surface stoichiometries of lithium-titanate spinel anodes.

\section{Methods}

Calculations were performed using the DFT code VASP, ${ }^{\mathbf{2 1 , 2 2}}$ with valence electrons described within a plane-wave basis and an energy cutoff of $500 \mathrm{eV}$. Valence-core interactions were treated with the projector augmented wave (PAW) method,, ${ }^{2324}$ with cores of $[\mathrm{Mg}]$ for $\mathrm{Ti},[\mathrm{He}]$ for $\mathrm{O}$, and $[\mathrm{He}]$ for $\mathrm{Li}$. Calculations were performed using the PBE generalised gradient approximation (GGA) functional, ${ }^{25}$ supplemented with a Dudarev $+U$ correction applied to the Ti d states $(\mathrm{GGA}+U)$. The previous study of $\mathrm{Lu}$ et al. presented EELS data for $\mathrm{Li}_{7} \mathrm{Ti}_{5} \mathrm{O}_{12}$ that showed distinct " $\mathrm{Ti}^{3+"}$ and " $\mathrm{Ti}^{4+"}$ " oxidation states, ${ }^{7}$ alongside DFT calculations using both standard GGA (PBE), and GGA $+U(\mathrm{PBE}+U)$ functionals. These GGA calculations qualitatively failed to describe the distinct Ti oxidation states observed in the EELS spectra. This is due to the self-interaction error inherent to standard GGA (and LDA) functionals, ${ }^{26-28}$ and similar behaviour is well known for many transition metal oxides with mixed formal oxidation states. ${ }^{29-31}$ By applying a $+U$ correction of $U=4.5 \mathrm{eV}$ to the Ti d states, Lu et al. predicted charge disproportionation into distinct " $\mathrm{Ti}^{3+}$ " and " $\mathrm{Ti}^{4+}$ " oxidation states, recovering qualitative agreement with the experimental EELS data. We use this same value of $U_{\mathrm{Ti}^{\mathrm{d}}}=4.5 \mathrm{eV}$, noting this is close to the value of $U_{\mathrm{Ti}^{\mathrm{d}}}=4.2 \mathrm{eV}$ used previously to study partially reduced $\mathrm{TiO}_{2} \cdot{ }^{32,32,33}$

To obtain equilibrium structures and reference energies for bulk $\mathrm{Li}_{4} \mathrm{Ti}_{5} \mathrm{O}_{12}$ and $\mathrm{Li}_{7} \mathrm{Ti}_{5} \mathrm{O}_{12}$, full geometry optimisations were performed for hexagonal cells with compositions $\mathrm{Li}_{8} \mathrm{Ti}_{10} \mathrm{O}_{24}$ and $\mathrm{Li}_{14} \mathrm{Ti}_{10} \mathrm{O}_{24}$ respectively, oriented with the close-packed (111) layers perpendicular to the $c$ axis. $k$-Point sampling used a $3 \times 3 \times 2$ Monkhorst-Pack mesh. Bulk $\alpha-\mathrm{Li}_{2} \mathrm{TiO}_{3}$ was modelled using $3 \sqrt{2} \times 3 \sqrt{2} \times 3$ supercells of $\mathrm{Li}_{24} \mathrm{Ti}_{12} \mathrm{O}_{36}$, with a $2 \times 3 \times 2$ Monkhorst-Pack mesh. All calculations were spinpolarised. Structures were deemed converged when all atomic forces were smaller than $0.01 \mathrm{eV}^{-1}$. For each structure zeropressure volumes were obtained by performing a series of constant-volume cell relaxations and fitting the resultant energy-volume data to the Murnaghan equation of state. The optimised bulk structures were used as starting points for the surface models. For all surface models, to minimise spurious slab-slab interactions a vacuum gap of at least $15 \AA$ a was placed between slab periodic images along the $c$ direction normal to the surface plane. The reference energy for metallic lithium, used to calculate surface energies as a function of the lithium chemical potential, was calculated using a body-centered cubic 2 -atom unit cell with a $16 \times 16 \times 16$ Monkhorst-Pack $k$ point mesh.

\section{Bulk structures}

\section{$\mathrm{Li}_{4} \mathrm{Ti}_{5} \mathrm{O}_{12}$ and $\mathrm{Li}_{7} \mathrm{Ti}_{5} \mathrm{O}_{12}$ structures}

$\mathrm{Li}_{4} \mathrm{Ti}_{5} \mathrm{O}_{12}$ and $\mathrm{Li}_{7} \mathrm{Ti}_{5} \mathrm{O}_{12}$ both consist of a cubic-close-packed oxide ion lattice with lithium and titanium ions occupying either tetrahedral or octahedral sites (Fig. 1(a)). In the lithiumpoor $\mathrm{Li}_{4} \mathrm{Ti}_{5} \mathrm{O}_{12}$ phase cations are distributed over the tetrahedral and octahedral sites to give a defective spinel structure. Lithium occupies all the tetrahedral 8a sites and one sixth of the octahedral 16d sites, and titanium occupies the remaining $16 \mathrm{~d}$ sites. The lithium-rich $\mathrm{Li}_{7} \mathrm{Ti}_{5} \mathrm{O}_{12}$ phase has the same $16 \mathrm{~d}$ site occupation (5:1 Ti : Li), but the tetrahedral 8 a sites are vacant. Instead the octahedral 16c sites are all occupied by lithium, giving a pseudo-rocksalt structure (Fig. 1(b)). 


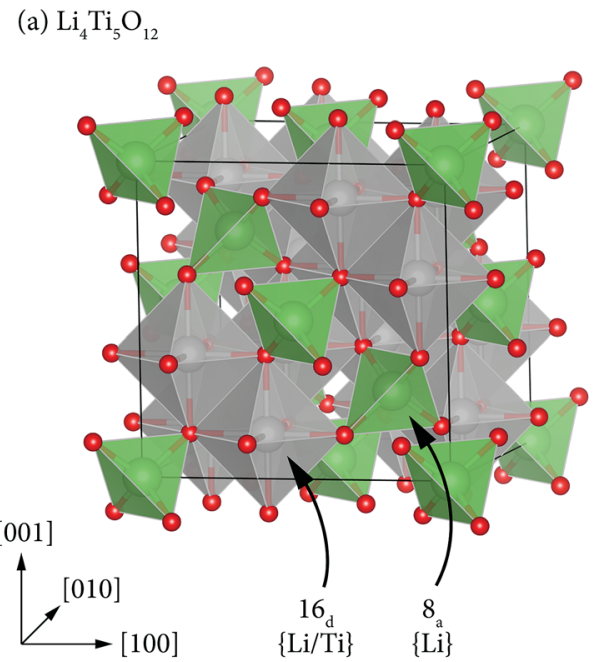

(b) $\mathrm{Li}_{7} \mathrm{Ti}_{5} \mathrm{O}_{12}$

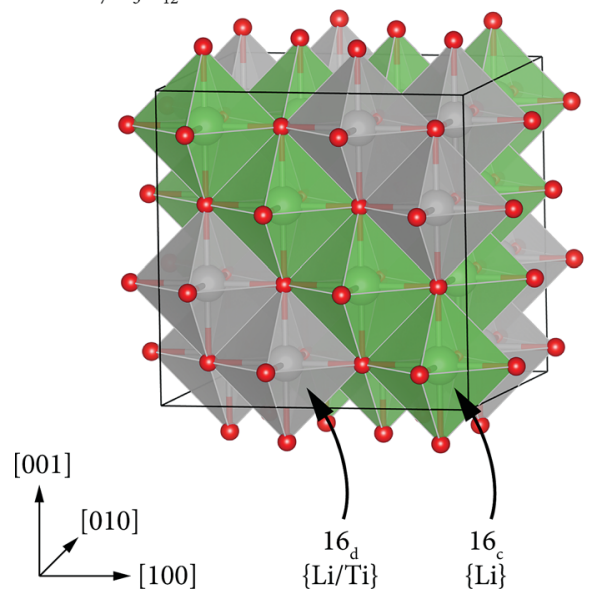

Fig. 1 Unit cells of (a) $\mathrm{Li}_{4} \mathrm{Ti}_{5} \mathrm{O}_{12}$ and (b) $\mathrm{Li}_{7} \mathrm{Ti}_{5} \mathrm{O}_{12}$. In both structures, oxygen ions (red) form an fcc lattice, occupying the 32e sites, and the $16 \mathrm{~d}$ octahedral sites (grey) are occupied by titanium and lithium at a ratio of $5: 1$. In (a) $\mathrm{Li}_{4} \mathrm{Ti}_{5} \mathrm{O}_{12}$, lithium also occupies the 8 a tetrahedra (green). In (b) $\mathrm{Li}_{7} \mathrm{Ti}_{5} \mathrm{O}_{12}$, all cations are in octahedral sites, with the $16 \mathrm{~d}$ octahedral sites (grey) occupied by titanium and lithium at a ratio of $5: 1$, and lithium in the $16 \mathrm{c}$ octahedra (green).

An alternative description of $\mathrm{Li}_{4} \mathrm{Ti}_{5} \mathrm{O}_{12}$ and $\mathrm{Li}_{7} \mathrm{Ti}_{5} \mathrm{O}_{12}$ considers hexagonal $\mathrm{Li}_{8} \mathrm{Ti}_{10} \mathrm{O}_{24}$ and $\mathrm{Li}_{14} \mathrm{Ti}_{10} \mathrm{O}_{24}$ cells. Each (111) layer has eight tetrahedral and four octahedral sites available to cations, which occupy these sites in (111) layers of [4 tetrahedra +2 octahedra] or [ 4 octahedra]..$^{34,35}$ The local structure depends on the specific distribution of lithium and titanium cations over these tetrahedral and octahedral lattice sites. In this work, we use the cation distributions first proposed by Lu et al. ${ }^{7}$ These authors used DFT calculations to optimise the distribution of lithium across the octahedral 16d sites in hexagonal cells containing two $\mathrm{Li}_{x} \mathrm{Ti}_{5} \mathrm{O}_{12}$ formula units, oriented with the (111) close-packed layers perpendicular to the cell $c$ direction. The reported lowest energy distribution of cations for this cell size corresponds to a six-layer ...ABCDCB... stacking sequence, where each layer differs in the number and site occupation of the lithium and titanium cations (Fig. 2). We have tested this $\mathrm{Li}_{4} \mathrm{Ti}_{5} \mathrm{O}_{12} \mathrm{Li} / \mathrm{Ti} 16 \mathrm{~d}$ arrangement for larger supercells by calculating energies for $2 \times 2 \times 1$ hexagonal supercells (192 atoms), and comparing the structure proposed by $\mathrm{Lu}$ et al. against 20 cells with random $16 \mathrm{~d} \mathrm{Li} / \mathrm{Ti}$ configurations. All 20 16d-disordered configurations had higher energies than the ordered arrangement proposed by Lu et al. We also calculated energies for the (100)-oriented $\mathrm{Li}_{4} \mathrm{Ti}_{5} \mathrm{O}_{12}$ cells proposed in separate works by Ouyang et al. ${ }^{4}$ and by Weber et $a .^{15}$ These structures also gave higher energies than the structure proposed by Lu et al. (full details are given in the ESI $\dagger$ ). These are zero-temperature calculations, and in experimental samples some site disorder is expected from entropy or because nonequilibrium cation distributions may be kinetically trapped (although the lithium cations are expected to be mobile ${ }^{36}$ ). Any disorder will make the (111) layers identified in Fig. 2 less distinct. Using the (111)-oriented model of $\mathrm{Lu}$ et al. therefore provides a limiting case with maximal differences between possible (111) surface terminations.

\section{$\alpha-\mathrm{Li}_{2} \mathrm{TiO}_{3}$ structure}

Under ambient conditions, $\mathrm{Li}_{2} \mathrm{TiO}_{3}$ preferentially adopts the monoclinic $\beta$ phase, which has been broadly studied due to potential applications as a microwave dielectric and as a possible tritium breeder in future fusion reactors. ${ }^{37-39}$ The $\alpha$ phase, which we are interested in here, is metastable in bulk systems. This phase can be considered a disordered pseudorocksalt, consisting of a fcc oxide-ion lattice with all the octahedral sites occupied by lithium or titanium. In this respect, $\alpha$ $\mathrm{Li}_{2} \mathrm{TiO}_{3}$ is similar to $\mathrm{Li}_{7} \mathrm{Ti}_{5} \mathrm{O}_{12}$, but with the octahedral sites are occupied in a $2: 1 \mathrm{Li}$ : Ti ratio.

To generate a bulk structure with a reasonable cation distribution we considered more than 40 different cation configurations in a $3 \sqrt{2} \times 3 \sqrt{2} \times 3$ supercell containing 12 $\mathrm{Li}_{2} \mathrm{TiO}_{3}$ formula units. By calculating the relative energies for each geometry-optimised structure we found that our lowest energy cation distribution at zero temperature (i.e. neglecting configurational entropy) corresponded to a structure with all $\langle 100\rangle$ and $\langle 110\rangle$ planes with $\mathrm{Li}_{2} \mathrm{TiO}_{3}$ stoichiometry. ${ }^{40}$

\section{(111) surface models}

To construct models of the $\mathrm{Li}_{x} \mathrm{Ti}_{5} \mathrm{O}_{12}$ (111) surfaces, the optimised bulk structures were cleaved along (111) planes to generate two-dimensional slab geometries. $\mathrm{Li}_{4} \mathrm{Ti}_{5} \mathrm{O}_{12}$ and $\mathrm{Li}_{7} \mathrm{Ti}_{5} \mathrm{O}_{12}$ have six-layer repeat unit [ABCDCB] stacking sequences along the [111] direction and any layer could, in principle, be chosen as a surface layer. The cation distribution means that each layer contains different numbers of lithium and titanium cations, and therefore has a different formal charge ( $c f$. Fig. 2). Hypothetical slabs with asymmetric layer sequences are therefore dipolar: their (111) surfaces are nonequivalent, leading to poorly defined surface energies. ${ }^{41}$ The asymmetric charge distribution corresponds to a dipole perpendicular to the surface planes, which introduces longranged dipole-dipole interactions between periodic slab images, and surface energies formally diverge with increasing slab thicknesses. To avoid these issues we consider only 
a) $\mathrm{Li}_{4} \mathrm{Ti}_{5} \mathrm{O}_{12}$

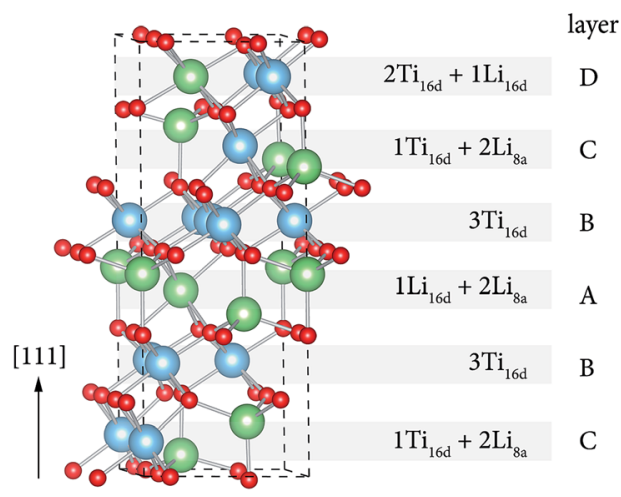

b) $\mathrm{Li}_{7} \mathrm{Ti}_{5} \mathrm{O}_{12}$

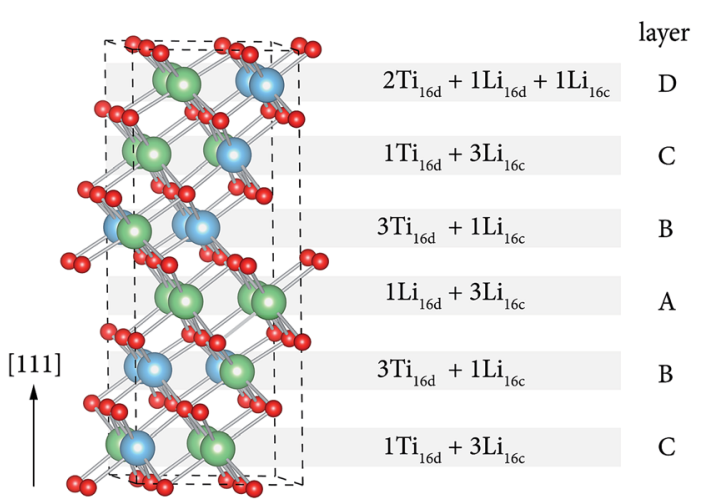

Fig. 2 Structures of (a) $\mathrm{Li}_{4} \mathrm{Ti}_{5} \mathrm{O}_{12}$, and (b) $\mathrm{Li}_{7} \mathrm{Ti}_{5} \mathrm{O}_{12}$, with the (111) close-packed direction oriented along $\mathrm{c}$. For each close-packed layer, the relative number of $\mathrm{Ti}$ and $\mathrm{Li}$ cations in each crystallographic site are given. Both structures can be considered an array of (111) close-packed layers, with [...ABCDCBA...] stacking sequence.

symmetric layer stacking sequences, which give non-polar slabs with well defined surface energies. In practice, this requires slabs with odd numbers of layers, and layers A or D at their centre. In the first instance, we consider surface models that maintain corresponding bulk stoichiometries, i.e. $\mathrm{Li}_{4} \mathrm{Ti}_{5} \mathrm{O}_{12}$ or $\mathrm{Li}_{7} \mathrm{Ti}_{5} \mathrm{O}_{12}$. This means surface energies are simply given by the difference in energies between the two-dimensional slabs and equivalent bulk systems, according to

$$
E_{\text {surface }}=\frac{1}{2 A}\left(E_{\text {slab }}-E_{\text {bulk }}\right),
$$

where $E_{\text {slab }}$ is the energy of the surface cell, $E_{\text {bulk }}$ is the energy of an equal number of formula units in the bulk, and $A$ is the surface area of one face in the slab model.

Surface stoichiometries may of course differ from those of the corresponding bulk phase. The large (111) surface unit cells of $\mathrm{Li}_{4} \mathrm{Ti}_{5} \mathrm{O}_{12}$ and $\mathrm{Li}_{7} \mathrm{Ti}_{5} \mathrm{O}_{12}$ mean that considering variable surface stoichiometries greatly increases the number of possible surfaces that could be constructed, beyond the already large number of surfaces to be considered under fixed stoichiometries. An exhaustive search over surface structures that takes into account variable stoichiometries, surface terminations, and surface structures is not computationally tractable within a first-principles approach. Below we show that the lowest energy stoichiometric (111) surfaces for $\mathrm{Li}_{4} \mathrm{Ti}_{5} \mathrm{O}_{12}$ and $\mathrm{Li}_{7} \mathrm{Ti}_{5} \mathrm{O}_{12}$ are lithium-terminated. To assess the relative stabilities of surfaces with variable lithium stoichiometries across relevant chemical conditions, we take these lowest-energy stoichiometric surfaces as templates, and then add or remove surface lithium at representative surface sites. The surface energies of the resulting non-stoichiometric surfaces depend on the lithium chemical potential, according to

$$
E_{\text {surface }}\left(\mu_{\mathrm{Li}}\right)=\frac{1}{2 A}\left(E_{\text {slab }}-E_{\text {bulk }}-\Delta n_{\mathrm{Li}}\left(E_{\mathrm{Li}}+\mu_{\mathrm{Li}}\right)\right),
$$

where $\Delta n_{\mathrm{Li}}$ is the number of lithium atoms added or removed at the surface, $E_{\mathrm{Li}}$ is the lithium reference energy, calculated for metallic bcc $\mathrm{Li}$, and $\mu_{\mathrm{Li}}$ is the lithium chemical potential. In a lithium-ion battery $\mu_{\mathrm{Li}}$ is equivalent to the cell voltage relative to metallic Li (scaled by Faraday's constant) in the limit that charging or discharging takes place reversibly.

Within the dual constraints of symmetric layer-stacking sequences and bulk stoichiometries, we initially constructed a range of seven-layer slabs with stacking sequences of (A)BCDCB(A) or (D)CBABC(D). B- and C-terminated slabs cannot be constructed with planar (111) surfaces to simultaneously be symmetric and have bulk stoichiometry. The surface layers, indicated in parentheses, appear twice: if all the constituent cations were included this would give the slabs stoichiometries different from the corresponding bulk phases. To maintain bulk stoichiometries, in each surface model half the cations were removed from one surface layer, (A) or (D), and moved to the opposite surface, following Tasker's method. ${ }^{42}$ This gives equivalent (symmetric) surface layers with half the cation occupancy of the corresponding bulk layers. The (111)-oriented $\mathrm{Li}_{7} \mathrm{Ti}_{5} \mathrm{O}_{12}$ unit cell has 4 octahedral cation sites (occupied) in each (111) layer. At the A-terminated and D-terminated surfaces, respectively, there are $4 \mathrm{Li}$ and $\{2 \mathrm{Li}+2 \mathrm{Ti}\}$ "under-coordinated" cations, and stoichiometric slab models with zero surfacenormal dipoles are generated by placing 2 of these cations $(2 \mathrm{Li}$ for the A-terminated surface, $1 \mathrm{Li}+1 \mathrm{Ti}$ for the D-terminated surface) on the opposite slab surface. In $\mathrm{Li}_{4} \mathrm{Ti}_{5} \mathrm{O}_{12}$, each (111) layer contains only three cations. To construct non-polar slab models with both surfaces equivalent we therefore used expanded $(2 \times 1)$ surface supercells for all $\mathrm{Li}_{4} \mathrm{Ti}_{5} \mathrm{O}_{12}$ surface calculations (Fig. 3). Our screening calculations used singlerepeat-unit slabs, corresponding to compositions of $\mathrm{Li}_{16} \mathrm{Ti}_{20} \mathrm{O}_{48}$ $\left(\mathrm{Li}_{4} \mathrm{Ti}_{5} \mathrm{O}_{12}\right)$ and $\mathrm{Li}_{14} \mathrm{Ti}_{10} \mathrm{O}_{24}\left(\mathrm{Li}_{7} \mathrm{Ti}_{5} \mathrm{O}_{12}\right)$.

Eliminating slab surface dipoles by symmetrically distributing the surface cations between both surfaces permits a number of possible cation arrangements at the surface: all of these formally remove the slab dipole because the two surfaces become stoichiometrically equivalent. Surface energies, however, can be expected to depend on the specific cation distribution for each partially coordinated surface layer. To explore this in detail, for each of the four studied $\mathrm{Li}_{x} \mathrm{Ti}_{5} \mathrm{O}_{12}(111)$ surfaces: $\mathrm{Li}_{4} \mathrm{Ti}_{5} \mathrm{O}_{12}(111)_{\mathrm{A}}, \mathrm{Li}_{4} \mathrm{Ti}_{5} \mathrm{O}_{12}(111)_{\mathrm{D}}, \mathrm{Li}_{7} \mathrm{Ti}_{5} \mathrm{O}_{12}(111)_{\mathrm{A}}$, 

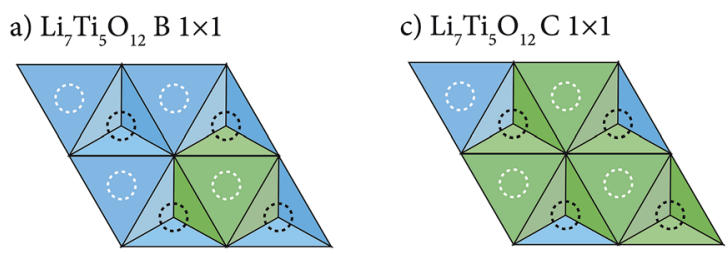

b) $\mathrm{Li}_{4} \mathrm{Ti}_{5} \mathrm{O}_{12} \mathrm{~B} 1 \times 2$

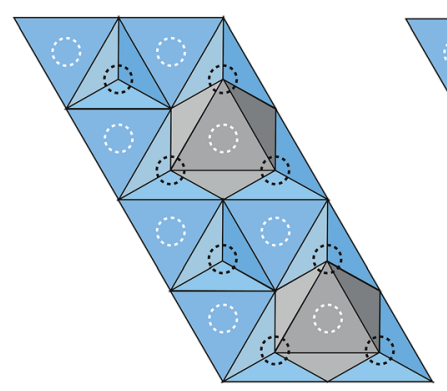

d) $\mathrm{Li}_{4} \mathrm{Ti}_{5} \mathrm{O}_{12} \mathrm{C} 1 \times 2$

Fig. 3 Schematic of the sub-surface unit cells used for generating the surface configurations. Blue and green polyhedra correspond to titanium and lithium occupied sites, respectively, and grey shows empty volume in the layer. Sites considered for the surface atoms are represented by dashed circles. White circles are surface tetrahedral sites, and black circles are surface octahedral sites. A-terminated surface models are constructed by partial occupation of the surface sites on the B sub-surface ( $a$ and $b$ ); D-terminated surface models are constructed by partial occupation of the surface sites on the $C$ sub-surface (c and d).

and $\mathrm{Li}_{7} \mathrm{Ti}_{5} \mathrm{O}_{12}(111)_{\mathrm{D}}$; we identified all symmetry inequivalent cation distributions commensurate with the appropriate stoichiometry and zero-dipole constraints.

The oxide sub-lattice in $\mathrm{Li}_{4} \mathrm{Ti}_{5} \mathrm{O}_{12}$ and $\mathrm{Li}_{7} \mathrm{Ti}_{5} \mathrm{O}_{12}$ is a facecentered cubic array. The (111) surfaces therefore can be considered a hexagonal lattice of sites with trigonal symmetry. Each surface site can be classified as "octahedral" or "tetrahedral", depending on whether it shares a (111) face with an octahedral site in the sub-surface layer (see Fig. 3). In each phase the cation sublattice arrangement of lithium and titanium lowers the surface symmetry. In particular, subsurface octahedral sites may be occupied by either lithium or by titanium, or in the case of $\mathrm{Li}_{4} \mathrm{Ti}_{5} \mathrm{O}_{12}$ may be unoccupied. This subsurface structure can be expected to influence the preferred arrangement of surface cations. A-terminated surfaces have subsurface B layers, and D-terminated surfaces have subsurface $\mathrm{C}$ layers. Taking into account the symmetry of the appropriate subsurface layer, we generated all symmetry-inequivalent surface cation configurations for each of the four stoichiometric surfaces considered, using the bsym symmetry analysis code. ${ }^{43}$ This gives 9 non-equivalent configurations for $\mathrm{Li}_{7} \mathrm{Ti}_{5} \mathrm{O}_{12}(\mathrm{~A}), 5$ configurations for $\mathrm{Li}_{7} \mathrm{Ti}_{5} \mathrm{O}_{12}(\mathrm{D}), 154$ configurations for $\mathrm{Li}_{4} \mathrm{Ti}_{5^{-}}$ $\mathrm{O}_{12}(\mathrm{~A})$, and 438 configurations for $\mathrm{Li}_{4} \mathrm{Ti}_{5} \mathrm{O}_{12}(\mathrm{D})$. Because of the large number of surface configurations for the $\mathrm{Li}_{4} \mathrm{Ti}_{5} \mathrm{O}_{12}$ slab models, these were initially optimised using a Ti PAW pseudopotential with a $[\mathrm{Ar}]$ core, before refining the structures of the 10 lowest energy configurations with the $[\mathrm{Mg}]$ core PAW pseudopotential.

\section{Results}

\section{Surface energies and preferred cation configurations}

Stoichiometric surfaces. The surface energies for A-terminated and D-terminated $\mathrm{Li}_{7} \mathrm{Ti}_{5} \mathrm{O}_{12}$ (111) slabs are plotted in Fig. 4. The surface energies for all the A-terminated slabs, which have only Li in the surface layer, are significantly lower than for the D-terminated slabs, which have mixed Li/Ti surfaces. This indicates a much greater energy cost for titanium versus lithium being under-coordinated at the surface.

The lowest energy configuration for the $\mathrm{Li}_{7} \mathrm{Ti}_{5} \mathrm{O}_{12}(111)_{\mathrm{A}}$ surface has half the surface lithium in tetrahedral sites that face-share with subsurface lithium octahedra, and half in octahedral sites (Fig. 4 (inset)). These are arranged in a hexagonal pattern that is consistent with minimising the Coulomb energy of the surface configuration: surface Li maximise their mutual separation, and only face-share with sub-surface sites containing single-valence lithium.

The larger surface cells necessary to maintain stoichiometry for the $\mathrm{Li}_{4} \mathrm{Ti}_{5} \mathrm{O}_{12}$ (111) surfaces give a large number of inequivalent structures. The surface energies of these are plotted in Fig. 5. As for the $\mathrm{Li}_{7} \mathrm{Ti}_{5} \mathrm{O}_{12}$ surfaces, the A-terminated surfaces, which only have Li surface cations, have much lower energies than the D-terminated mixed Li/Ti-terminated surfaces. A large number of low energy configurations exist, with representative surface cation arrangements shown in Fig. 5 . These surface configurations are equivalent by symmetry, and are similar to the hexagonal arrangement found for $\mathrm{Li}_{7} \mathrm{Ti}_{5} \mathrm{O}_{12}(111)_{\mathrm{A}}$. Two thirds of the surface Li occupy tetrahedral sites that face-share with vacant sub-surface octahedra, and the remaining third of the surface Li occupy octahedral surface sites, avoiding facesharing with sub-surface Ti octahedra. This arrangement gives a partial hexagonal motif. The large number of sampled configurations with very similar low energies is due to lithium ions initially placed close to the empty sub-surface octahedral site each relaxing to the face-sharing tetrahedral site.

Our focus on stoichiometric surfaces means our calculation set excludes non-stoichiometric B- and C-terminated (111)

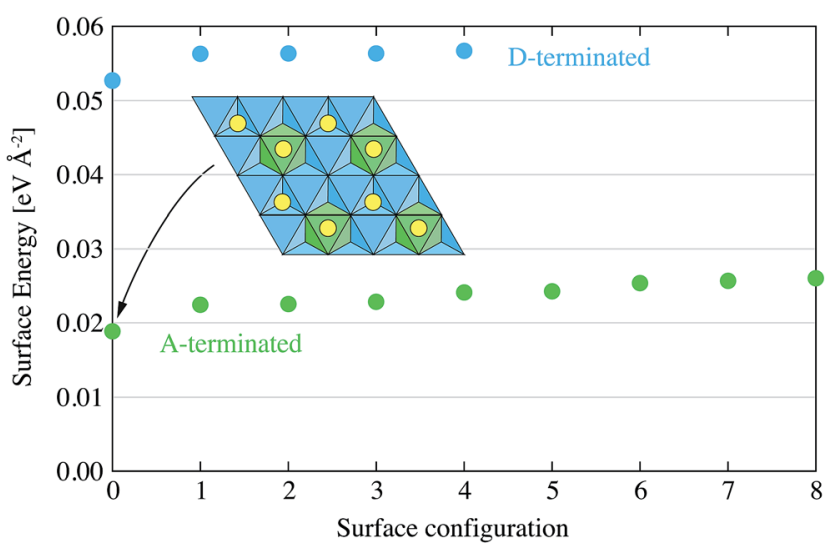

Fig. 4 Surface energies in eV $\AA^{-2}$ of the A-terminated and D-terminated $\mathrm{Li}_{7} \mathrm{Ti}_{5} \mathrm{O}_{12}$ (111) surface slabs. Blue and green octahedra show titanium and lithium occupied subsurface sites, respectively. Yellow circles show lithium positions. 

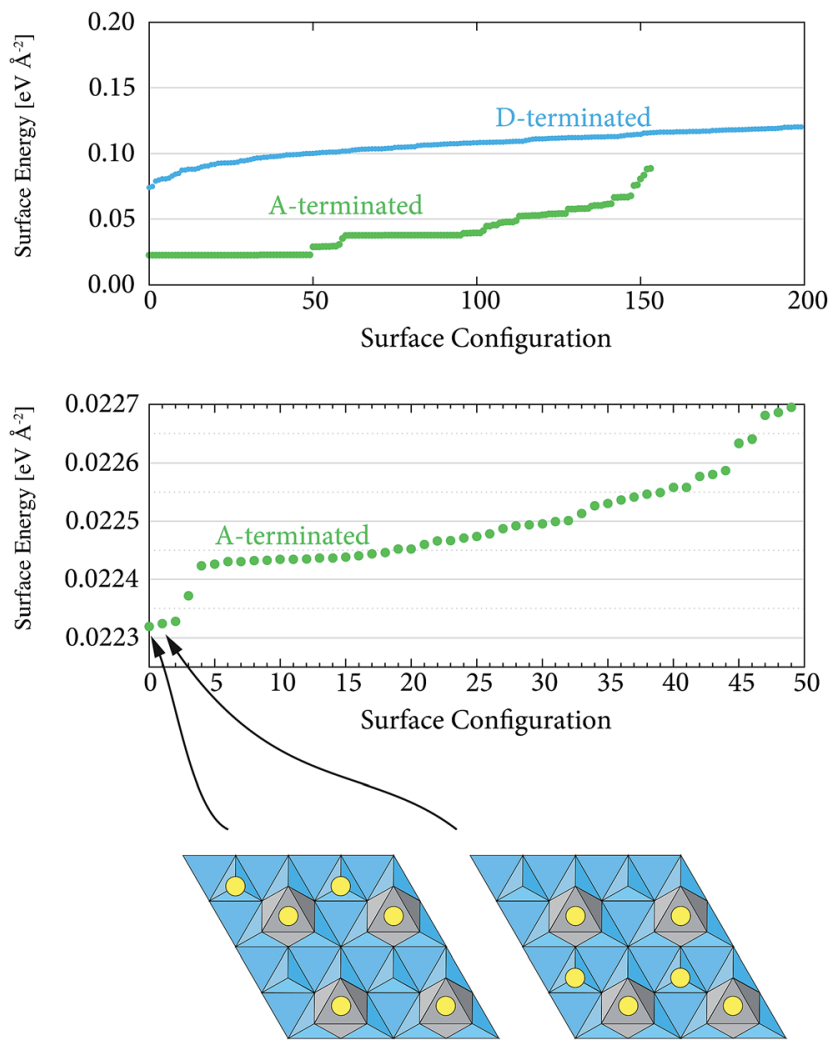

Fig. 5 Top panel: Surface energies in $\mathrm{eV} \AA^{-2}$ of the A-terminated and $D$-terminated $\mathrm{Li}_{4} \mathrm{Ti}_{5} \mathrm{O}_{12}$ (111) oriented surface slabs. Only data for the 200 lowest energy D-terminated surfaces are shown. Middle panel: Surface energies of the 50 lowest energy A-terminated surfaces. These data were calculated using the [Ar] core pseudopotential for $\mathrm{Ti}$. Bottom panel: The lowest surface energy configurations for $\mathrm{Li}_{4} \mathrm{Ti}_{5} \mathrm{O}_{12}$ (A-terminated). Blue and grey octahedra show titanium-occupied and vacant subsurface sites, respectively. Yellow circles show lithium positions.

surfaces. The B- and C-terminated surfaces would present under-coordinated surface Ti atoms ( $c f$. Fig. 2), similarly to the included D-terminated surfaces. Because the D-terminated (Li/ Ti) surfaces have larger surface energies than the A-terminated (purely Li) surfaces, we expect the B- and C-terminated (111) surfaces to also be disfavoured with respect to the A-terminated surfaces for both $\mathrm{Li}_{4} \mathrm{Ti}_{5} \mathrm{O}_{12}$ and $\mathrm{Li}_{7} \mathrm{Ti}_{5} \mathrm{O}_{12}$. A second consideration is that while the observed surface reconstructions observed for many of the D-terminated surfaces do not lower the surface energy enough to become competitive with the Aterminated surfaces, more complex reconstructions to low energy surface terminations might exist. To examine this possibility, a broader search over surface configurations would be necessary, using more sophisticated structure prediction methods such as evolutionary algorithms. ${ }^{44,45}$

The calculated surface energies for the lowest energy $\mathrm{Li}_{4} \mathrm{Ti}_{5} \mathrm{O}_{12}$ and $\mathrm{Li}_{7} \mathrm{Ti}_{5} \mathrm{O}_{12}$ (111) surfaces are compared to the $\alpha$ $\mathrm{Li}_{2} \mathrm{TiO}_{3}$ (100), (110), and (111) surface energies in Table 1. For $\mathrm{Li}_{4} \mathrm{Ti}_{5} \mathrm{O}_{12}$ and $\mathrm{Li}_{7} \mathrm{Ti}_{5} \mathrm{O}_{12}$ (111) the surface energies are $0.022 \mathrm{eV}$ $\AA^{-2}$ and $0.038 \mathrm{eV} \AA^{-2}$ respectively. These surface energies are much lower than those previously calculated by Weber $e t$ al.
Table 1 Calculated surface energies for the considered $\mathrm{Li}_{4} \mathrm{Ti}_{5} \mathrm{O}_{12}$, $\mathrm{Li}_{7} \mathrm{Ti}_{5} \mathrm{O}_{12}$, and $\alpha-\mathrm{Li}_{2} \mathrm{TiO}_{3}$ surfaces. For the low energy $\mathrm{Li}_{4} \mathrm{Ti}_{5} \mathrm{O}_{12}$ (111), $\mathrm{Li}_{7} \mathrm{Ti}_{5} \mathrm{O}_{12}$ (111), and $\alpha-\mathrm{Li}_{2} \mathrm{TiO}_{3}(100)$ surfaces, doubling the slab model thickness to 13 layers for $\mathrm{Li}_{x} \mathrm{Ti}_{5} \mathrm{O}_{12}$ and to 12 layers for $\alpha-\mathrm{Li}_{2} \mathrm{TiO}_{3}(100)$ changed the calculated surface energy by less than $4 \mathrm{meV} \AA^{-2}$. * Indicates the $\alpha-\mathrm{Li}_{2} \mathrm{TiO}_{3}$ (111) surface, which underwent significant surface reconstruction

\begin{tabular}{ll}
\hline Surface & Energy $\left[\mathrm{eV} \AA^{-2}\right]$ \\
\hline $\mathrm{Li}_{4} \mathrm{Ti}_{5} \mathrm{O}_{12}(111)$ & 0.022 \\
$\mathrm{Li}_{7} \mathrm{Ti}_{5} \mathrm{O}_{12}(111)$ & 0.038 \\
$\alpha-\mathrm{Li}_{2} \mathrm{TiO}_{3}(100)$ & 0.039 \\
$\alpha-\mathrm{Li}_{2} \mathrm{TiO}_{3}(110)$ & 0.118 \\
$\alpha-\mathrm{Li}_{2} \mathrm{TiO}_{3}(111)$ & $0.091^{*}$ \\
\hline
\end{tabular}

using PBE, who reported energies of $0.106 \mathrm{eV} \AA^{-2}$ and $0.105 \mathrm{eV}$ $\AA^{-2}$ respectively. ${ }^{15,46}$ This previous study considered only a single slab geometry for each stoichiometry and surface orientation. The much lower surface energies for the most stable surfaces considered here suggest that the surface models used in this previous work correspond to unstable high energy surface terminations. This difference in calculated values illustrates the need to consider competing surface terminations when modelling surfaces of materials with complex unit cells.

For $\alpha-\mathrm{Li}_{2} \mathrm{TiO}_{3}$, the (111) surface energy is significantly higher than the $\mathrm{Li}_{x} \mathrm{Ti}_{5} \mathrm{O}_{12}$ (111) surface energies, at $0.091 \mathrm{eV} \AA^{-2}$. This $\alpha-\mathrm{Li}_{2} \mathrm{TiO}_{3}$ surface underwent a spontaneous disordered reconstruction of the surface and sub-surface layers during geometry optimisation. The (110) surface energy is similarly disfavourable, at $0.118 \mathrm{eV} \AA^{-2}$. The (100) $\alpha-\mathrm{Li}_{2} \mathrm{TiO}_{3}$ surface however has a much smaller surface energy of $0.039 \mathrm{eV} \AA^{-2}$, which is not unexpected for a (pseudo)-rocksalt structure, ${ }^{47}$ and is now comparable to the $\mathrm{Li}_{7} \mathrm{Ti}_{5} \mathrm{O}_{12}$ (111) surface energy. Surface phases of $\alpha-\mathrm{Li}_{2} \mathrm{TiO}_{3}$ are therefore predicted to preferentially express (100) surfaces, and formation of $\alpha-\mathrm{Li}_{2} \mathrm{TiO}_{3}$ on (111)-oriented $\mathrm{Li}_{x} \mathrm{Ti}_{5} \mathrm{O}_{12}$ is expected to produce highly facetted morphologies, which provides a possible explanation for the greatly increased surface roughness observed with $\alpha-\mathrm{Li}_{2} \mathrm{TiO}_{3}$ surface phase formation by Kitta et al. ${ }^{11}$

Non-stoichiometric surfaces. Thus far we have considered only stoichiometric surface models. This restricts the possible surfaces to a number that is computationally tractable and simplifies the surface-energy analysis, because the calculated surface energies are independent of the component chemical potentials. Lithium-ion batteries are dynamic systems, however, and it is important to consider the stabilities of competing surfaces under chemical conditions corresponding to cell operation. In particular, the lithium chemical potential, which is proportional to the cell voltage in the limit of reversible charging and discharging, may vary by several $\mathrm{eV}$ during cell cycling.

To investigate the effect of chemical conditions on surface stability, we took as starting templates the lowest energy stoichiometric surface models, and constructed a series of surface models with lithium added to or removed from the surface layer. As described above, for both $\mathrm{Li}_{4} \mathrm{Ti}_{5} \mathrm{O}_{12}$ and $\mathrm{Li}_{7} \mathrm{Ti}_{5} \mathrm{O}_{12}$ the stoichiometric (111) surfaces are more stable when 
Li-terminated than with mixed $\mathrm{Li} / \mathrm{Ti}$-termination, and we therefore only consider variable lithium-ion surface coverage. We have not performed an exhaustive search of all possible surface configurations and stoichiometries. Instead we use the subset of surface sites occupied in the lowest energy stoichiometric configurations as templates for representative non-stoichiometric structures.

In the lowest energy $\mathrm{Li}_{7} \mathrm{Ti}_{5} \mathrm{O}_{12}$ configuration, the surfacelayer lithium is arranged in a hexagonal pattern (Fig. 4). The lowest energy $\mathrm{Li}_{4} \mathrm{Ti}_{5} \mathrm{O}_{12}$ configuration displays a similar hexagonal motif, but with some lithium vacancies. In each case, we consider surface models with additional surface lithium placed either in the centre of these hexagons $\left(\mathrm{Li}_{7} \mathrm{Ti}_{5} \mathrm{O}_{12}\right)$ or completing the hexagonal pattern $\left(\mathrm{Li}_{4} \mathrm{Ti}_{5} \mathrm{O}_{12}\right)$. Within the $\mathrm{DFT}+U$ approach (with $U_{\mathrm{Ti}^{\mathrm{d}}}=4.5 \mathrm{eV}$ ), adding surface Li donates additional electrons to the oxide substrate, which are localised at " $\mathrm{Ti}^{3+}$ " centres. Both $\mathrm{Li}_{4} \mathrm{Ti}_{5} \mathrm{O}_{12}$ and $\mathrm{Li}_{7} \mathrm{Ti}_{5} \mathrm{O}_{12}$ have stoichiometric lowest-energy (111) surfaces where lithium occupies two crystallographically distinct surface sites. For each phase, we consider pairs of lithium-deficient surfaces with only one of these sites occupied, and also a fully lithium-deficient surface termination (Fig. 6).

Fig. 7 plots the surface energies for these variable lithiumcoverage surfaces, calculated using eqn (2), versus lithium chemical potential, $\mu_{\mathrm{Li}}$. To identify relevant ranges of $\mu_{\mathrm{Li}}$, we have calculated the chemical potential spaces where $\mathrm{Li}_{4} \mathrm{Ti}_{5} \mathrm{O}_{12}$ is thermodynamically stable with respect to rutile $\mathrm{TiO}_{2}$ and $\mathrm{Li}_{7} \mathrm{Ti}_{5} \mathrm{O}_{12}$, and where $\mathrm{Li}_{7} \mathrm{Ti}_{5} \mathrm{O}_{12}$ is thermodynamically stable with respect to $\mathrm{Li}_{4} \mathrm{Ti}_{5} \mathrm{O}_{12}$ and $\mathrm{Li}_{2} \mathrm{O}$. The lithium chemicalpotential ranges where each phase is thermodynamically unstable are shaded grey in Fig. 7.

For $\mathrm{Li}_{4} \mathrm{Ti}_{5} \mathrm{O}_{12}$, the stoichiometric surface is most stable over the full stability range of $\mu_{\mathrm{Li}}$. Kitta et al. have used STM to characterise $\mathrm{Li}_{4} \mathrm{Ti}_{5} \mathrm{O}_{12}$ (111) surfaces under ambient conditions, ${ }^{35}$ and observed a hexagonal pattern of points (attributed to surface lithium) separated by $0.6 \mathrm{~nm}$. This pattern would be consistent with either of the partially lithium-deficient $\mathrm{Li}_{4} \mathrm{Ti}_{5} \mathrm{O}_{12}$ (111) surface models. Our calculations indicate that these surfaces are only stable at particularly low lithium chemical potentials, where bulk $\mathrm{Li}_{4} \mathrm{Ti}_{5} \mathrm{O}_{12}$ is thermodynamically unstable with respect to $\mathrm{TiO}_{2}$. This suggests that these observed ex situ non-stoichiometric defective samples may be kinetically stabilised, and might not be representative of the same materials under charging/discharging conditions.

For $\mathrm{Li}_{7} \mathrm{Ti}_{5} \mathrm{O}_{12}$ the stoichiometric surface is favoured over nearly the whole region of thermodynamic stability. Within a narrow region of relatively low $\mu_{\mathrm{Li}}$ however, close to the stability limit with respect to $\mathrm{Li}_{4} \mathrm{Ti}_{5} \mathrm{O}_{12}$, partially lithium-deficient surfaces become favoured relative to the stoichiometric surfaces.

\section{Electronic properties and thermodynamic reduction drive}

The different structures and compositions of competing electrode surfaces correspond to different local potential profiles and electronic structures. These electronic differences are responsible for varied electrochemical behaviour with respect to lithium (de)intercalation, SEI formation, and overall electrode lifetimes. Surfaces with high electron chemical potentials-or equivalently, small workfunctions - should, if solvent relaxation effects are neglected, exhibit a more pronounced thermodynamic drive towards reduction of organic electrolytes, and might promote SEI formation even in the absence of an external applied voltage. ${ }^{\mathbf{4 , 2 0}}$ The atomistic details of such processes are at present far from clear. In particular it is unknown to what degree zero-bias (equilibrium formed) SEI's can perform better than SEI's formed during lithium-cycling i.e. via non-equilibrium chemistry. Computational modelling offers direct access to the electron chemical potential at different surfaces, and allows us to explore the scope of possible electronic behaviours. Furthermore, by identifying surfaces with noteworthy reduction potentials, we hope to stimulate experimental studies of zerobias SEI formation in the context of possible improvements to lithium-ion cell stabilities.

Having identified the low energy surface terminations for $\mathrm{Li}_{4} \mathrm{Ti}_{5} \mathrm{O}_{12}$ (111) and $\mathrm{Li}_{7} \mathrm{Ti}_{5} \mathrm{O}_{12}$ (111), and found the (100) surface preferred for $\alpha-\mathrm{Li}_{2} \mathrm{TiO}_{3}$, we calculated vacuum-aligned energies
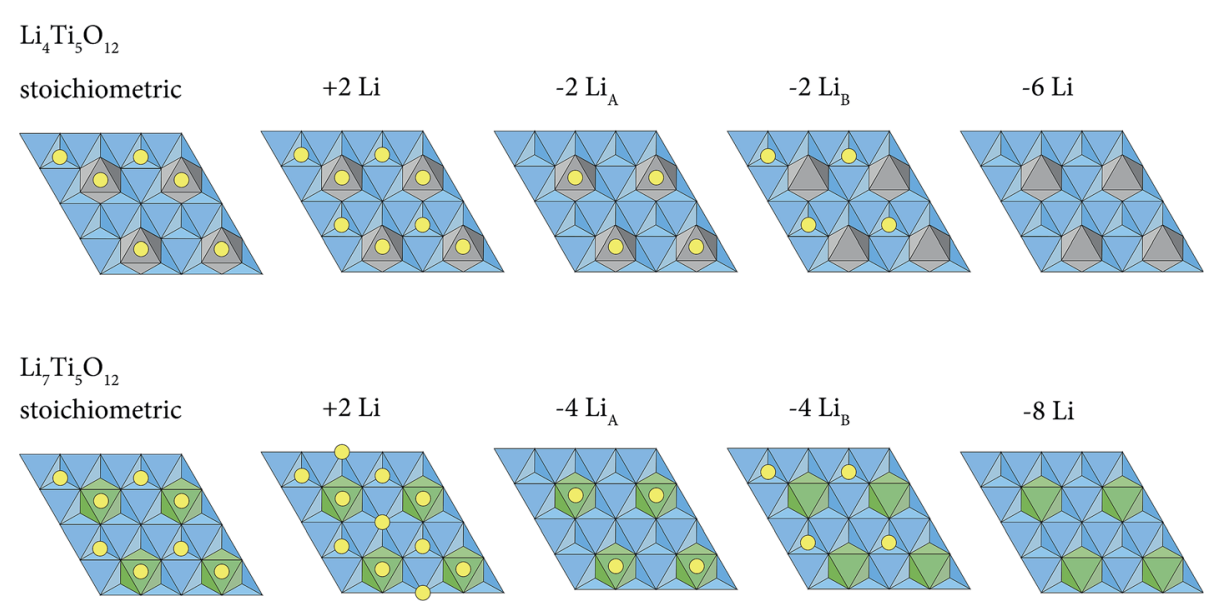

Fig. 6 Schematic of the stoichiometric and variable lithium-coverage A-terminated surface models that were calculated for $\mathrm{Li}_{4} \mathrm{Ti}_{5} \mathrm{O}_{12}$ and $\mathrm{Li}_{7} \mathrm{Ti}_{5} \mathrm{O}_{12}$. 
a) $\mathrm{Li}_{4} \mathrm{Ti}_{5} \mathrm{O}_{12}$

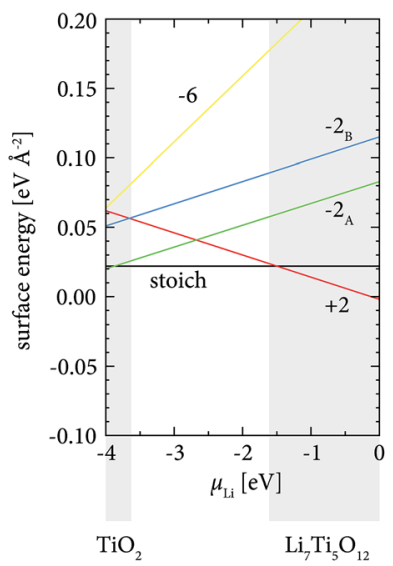

b) $\mathrm{Li}_{7} \mathrm{Ti}_{5} \mathrm{O}_{12}$

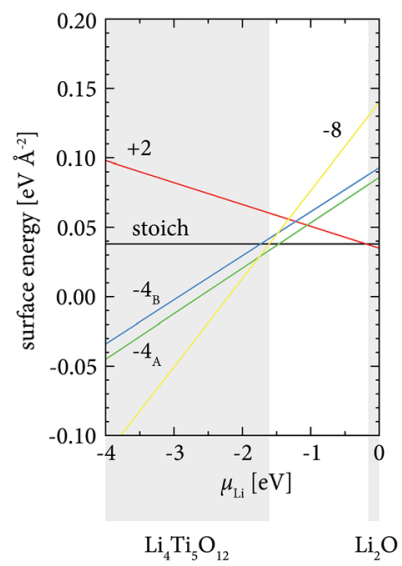

Fig. $7 \quad \mu_{\mathrm{Li}}$-Dependent surface energies for $\mathrm{A}$-terminated $\mathrm{Li}_{4} \mathrm{Ti}_{5} \mathrm{O}_{12}$ and $\mathrm{Li}_{7} \mathrm{Ti}_{5} \mathrm{O}_{12}$ (111) surfaces. The shaded regions show lithium chemical potentials where $\mathrm{Li}_{4} \mathrm{Ti}_{5} \mathrm{O}_{12}$ and $\mathrm{Li}_{7} \mathrm{Ti}_{5} \mathrm{O}_{12}$ are predicted to be thermodynamically unstable for unconstrained oxygen/titanium chemical potentials.

Table 2 Calculated vacuum-aligned highest-occupied state energies for the $\mathrm{Li}_{4} \mathrm{Ti}_{5} \mathrm{O}_{12}$ (111), $\mathrm{Li}_{7} \mathrm{Ti}_{5} \mathrm{O}_{12}$ (111), and $\alpha-\mathrm{Li}_{2} \mathrm{TiO}_{3}$ (100) surfaces (13, 13,12 layers). Convergence of $E_{\mathrm{HOS}}^{\mathrm{vac}}$ with respect to slab thickness is less than $70 \mathrm{meV}$ in all cases, from comparison with values for halfthickness slabs $(7,7,6$ layers)

\section{Surface}

$\mathrm{Li}_{4} \mathrm{Ti}_{5} \mathrm{O}_{12}(111)$

$\mathrm{Li}_{7} \mathrm{Ti}_{5} \mathrm{O}_{12}(111)$

$\alpha-\mathrm{Li}_{2} \mathrm{TiO}_{3}(100)$

for the highest occupied Kohn-Sham states for these three surfaces, to estimate the thermodynamic reduction drive in each case. These energies, $E_{\mathrm{HOS}}^{\mathrm{vac}}$ were calculated for each slab as the difference between the electrostatic potential plateau for the vacuum and the energy of the highest occupied Kohn-Sham state, $E_{\mathrm{HOKSS}}{ }^{48,49}$

$$
E_{\mathrm{HOS}}^{\mathrm{vac}}=E_{\mathrm{HOKSS}}-E_{\mathrm{vacuum}} .
$$

The vacuum potential and highest-occupied-state energies were calculated in each case using a geometry-optimised "doublethickness" surface slab: 13 layers for $\mathrm{Li}_{4} \mathrm{Ti}_{5} \mathrm{O}_{12}$ and $\mathrm{Li}_{7} \mathrm{Ti}_{5} \mathrm{O}_{12}$ (111) and 12 layers for $\alpha-\mathrm{Li}_{2} \mathrm{TiO}_{3}$ (100).

The calculated highest-occupied state energies, $E_{\mathrm{HOS}}^{\mathrm{vac}}$ (Table 2) reveal a significant difference between $\mathrm{Li}_{4} \mathrm{Ti}_{5} \mathrm{O}_{12}$ (111) and $\mathrm{Li}_{7} \mathrm{Ti}_{5} \mathrm{O}_{12}$ (111) of $\Delta E_{\mathrm{HOS}}^{\mathrm{vac}}=2.66 \mathrm{eV}$. This difference between $\mathrm{Li}_{4} \mathrm{Ti}_{5} \mathrm{O}_{12}$ and $\mathrm{Li}_{7} \mathrm{Ti}_{5} \mathrm{O}_{12}$ can be understood by considering the electronic densities of states (Fig. 8). In $\mathrm{Li}_{4} \mathrm{Ti}_{5} \mathrm{O}_{12}$ all the titanium is in a formal +4 oxidation state, with the Ti $3 \mathrm{~d}$ states unoccupied, making the highest occupied state the $\mathrm{O} 2 \mathrm{p}$ dominated valence band edge. In $\mathrm{Li}_{7} \mathrm{Ti}_{5} \mathrm{O}_{12}$, however, the additional lithium is charge-compensated by electrons that partially reduce the titanium, producing the " $\mathrm{Ti}^{3+}$ " characteristics identified in the LEED

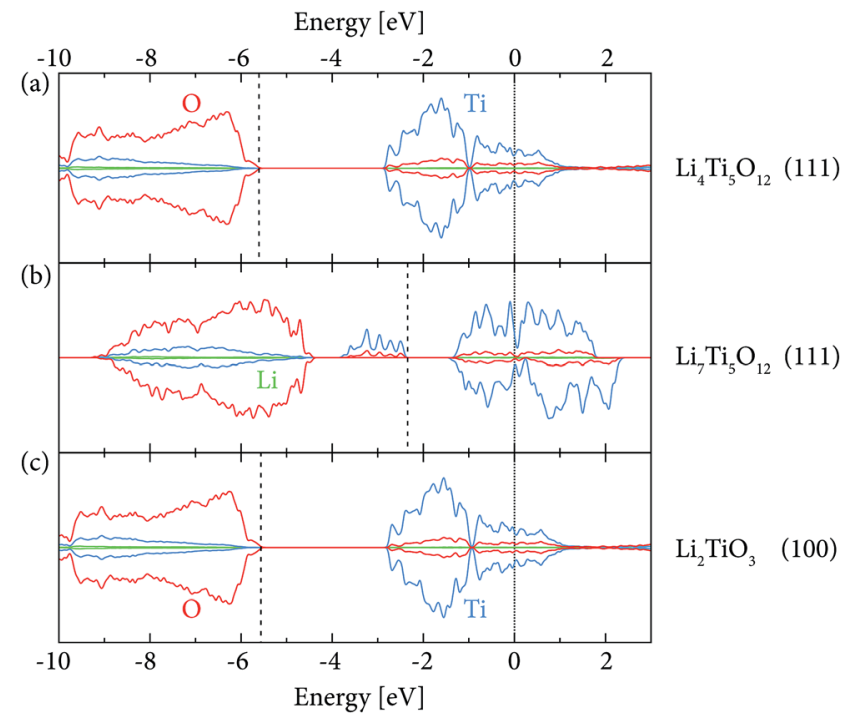

Fig. 8 Projected densities of states for the (a) $\mathrm{Li}_{4} \mathrm{Ti}_{5} \mathrm{O}_{12}$ (111), (b) $\mathrm{Li}_{7} \mathrm{Ti}_{5} \mathrm{O}_{12}$ (111), and (c) $\alpha-\mathrm{Li}_{2} \mathrm{TiO}_{3}$ (100) surface slabs (13, 13, 12 layers). In each case the energy scale uses the vacuum energy as zero, shown with the solid vertical line. The energies of the highest occupied states are shown with dashed vertical lines. Contributions from Li s are shown in green, $\mathrm{O} p$ in red, and $\mathrm{Ti} d$ in blue.

data of $\mathrm{Lu}$ et al. ${ }^{7}$ These occupied $\mathrm{Ti}^{3+}$ states reside in the band gap, moving the highest occupied states $2 \mathrm{eV}$ above the valence band edge. In addition, the valence and conduction bands are shifted up in energy relative to their positions in $\mathrm{Li}_{4} \mathrm{Ti}_{5} \mathrm{O}_{12}{ }^{50}$ The large increase in $E_{\mathrm{HOS}}^{\mathrm{vac}}$ for $\mathrm{Li}_{7} \mathrm{Ti}_{5} \mathrm{O}_{12}$ is therefore due to occupied band-gap states that lie close to the vacuum level. For $\alpha-\mathrm{Li}_{2} \mathrm{TiO}_{3}$ $E_{\mathrm{HOS}}^{\mathrm{vac}}$ is $-4.71 \mathrm{eV}$; more than $2 \mathrm{eV}$ lower than for $\mathrm{Li}_{7} \mathrm{Ti}_{5} \mathrm{O}_{12}(111)$. Despite the higher lithium content, $\mathrm{Li}_{2} \mathrm{TiO}_{3}$ contains titanium only with a formal +4 oxidation state, and correspondingly the density of states shows no occupied titanium band-gap states (Fig. 8(c)), giving a valence band edge position comparable to that of $\mathrm{Li}_{4} \mathrm{Ti}_{5} \mathrm{O}_{12}$. For all three slabs the projected densities of states, generated by projecting onto the PAW projectors, show partial mixing between $\mathrm{Ti} \mathrm{d}$ and $\mathrm{O} \mathrm{p}$ states, with very little contribution from Li s states. This is consistent with stronger covalent interactions between $\mathrm{Ti}-\mathrm{O}$ than $\mathrm{Li}-\mathrm{O}$, and hence a larger energy penalty for "dangling bonds" at under-coordinated Ti versus $\mathrm{Li}$, in line with the large surface energies and tendency for spontaneous reconstruction of the Ti-terminated $\mathrm{Li}_{x} \mathrm{Ti}_{5} \mathrm{O}_{12}$ (111) slabs.

Taking $E_{\mathrm{HOS}}^{\mathrm{vac}}$ of the vacuum exposed surfaces as an approximation to their reduction potential, and neglecting electrolyte adsorption effects, the low values of $E_{\mathrm{HOS}}^{\mathrm{vac}}$ for $\mathrm{Li}_{4} \mathrm{Ti}_{5} \mathrm{O}_{12}$ (111) and $\alpha-\mathrm{Li}_{2} \mathrm{TiO}_{3}$ (100) versus $\mathrm{Li}_{7} \mathrm{Ti}_{5} \mathrm{O}_{12}$ (111) suggest that the thermodynamic drive for electrolyte reduction at these surfaces is much smaller than at the $\mathrm{Li}_{7} \mathrm{Ti}_{5} \mathrm{O}_{12}$ (111) surface. ${ }^{51}$ Where $\alpha-\mathrm{Li}_{2} \mathrm{TiO}_{3}$ forms as a surface phase during lithium cycling, as described, for example, by Kitta et al., this therefore may be expected to act as an effective SEI layer that stabilises the electrode against reductive electrolyte decomposition, and potentially improves electrode stability with respect to repeated charge-cycling. 
In contrast, the high value of $E_{\mathrm{HOS}}^{\mathrm{vac}}=-2.56 \mathrm{eV}$ for $\mathrm{Li}_{7} \mathrm{Ti}_{5} \mathrm{O}_{12}$ (111) is notable in having a smaller magnitude than the work function of polycrystalline elemental lithium of $\sim 2.9 \mathrm{eV}$ (ref. 17 and 52) indicating an extreme drive for reduction at the pristine $\mathrm{Li}_{7} \mathrm{Ti}_{5} \mathrm{O}_{12}$ (111) surface. Within the approximations of this approach, we expect this to correspond to a strong tendency for electrolyte reduction and SEI formation. ${ }^{53}$ Based on recent advances in local characterization of Li-titanate electrodes by scanning probe microscopies, ${ }^{54}$ this prediction could be the object of future experimental investigations.

Hirayama et al. have previously studied SEI formation and structural changes at $\mathrm{LiMn}_{2} \mathrm{O}_{4}$ cathode surfaces during initial electrolyte wetting and subsequent lithium cycling, using in situ surface XRD and high-resolution TEM. ${ }^{19}$ During initial soaking (i.e. under zero bias) the (111) surface of $\mathrm{LiMn}_{2} \mathrm{O}_{4}$ reacts with the electrolyte to form a dense flat SEI layer. This SEI-encapsulated (111) surface was stable with respect to electrode deterioration during subsequent lithium cycling. In contrast, electrolyte wetting of the $\mathrm{LiMn}_{2} \mathrm{O}_{4}$ (110) surface did not form a SEI layer, and during the first lithium charge Mn ions dissolved into the electrolyte-a process associated with electrode degradation. These authors suggested the behaviour of the SEIencapsulated (111) surface may be due to direct contact between the electrode and electrolyte being blocked by the SEI layer, providing a more stable electrochemical interface, or due to the SEI layer inducing a structural transition at the (111) surface that inhibits Mn dissolution. Irrespective of the mechanism, SEI formation under zero bias at the $\mathrm{LiMn}_{2} \mathrm{O}_{4}$ (111) surface is correlated with improved electrode stability during lithium cycling. Recent DFT calculated values of $E_{\mathrm{HOS}}^{\mathrm{vac}}$ for the $\mathrm{LiMn}_{2} \mathrm{O}_{4}$ (001) and (111) surfaces (following the same approach used here) have found a less negative (smaller magnitude) value for the (111) surface, indicating a larger reduction drive at this surface compared to the (001) surface. ${ }^{20}$ When considered alongside the experimental data of Hirayama et al., these results suggest a possible correlation between surface reduction drive, propensity for SEI formation under zero-bias, and subsequent electrochemical performance of the SEI-protected electrode. In this context, we note that $\mathrm{He}$ et al. provide experimental evidence for zero-bias SEI formation on $\mathrm{Li}_{4} \mathrm{Ti}_{5} \mathrm{O}_{12},{ }^{55}$ albeit with no electrochemical characterisation. In concert with the observations of Hirayama et al., this suggests the possibility of zero-bias SEI formation for both cathodic and anodic metal oxide surfaces.

In the specific case of $\mathrm{Li}_{x} \mathrm{Ti}_{5} \mathrm{O}_{12}$, the reduction drive for the pristine $\mathrm{Li}_{7} \mathrm{Ti}_{5} \mathrm{O}_{12}$ (111) surface is calculated to be even greater than that of metallic lithium, and we predict that this surface will spontaneously reduce common electrolytes under equilibrium conditions. Extrapolating from the study of Hirayama et al. we hypothesise that a "zero-bias" SEI formed at this surface may be highly stable, because its formation would not require a driving external potential, and could enhance the cycle lifetime of the underlying electrode. This proposal requires a pristine $\mathrm{Li}_{7} \mathrm{Ti}_{5} \mathrm{O}_{12}$ (111) (substrate or coating) exposed to the electrolyte. In the study of Kitta et al. ${ }^{11}$ the electrochemical cell was constructed using $\mathrm{Li}_{4} \mathrm{Ti}_{5} \mathrm{O}_{12}$, and a $\alpha-\mathrm{Li}_{2} \mathrm{TiO}_{3}$ surface layer forms upon electrochemical intercalation, which then separates the (now buried) $\mathrm{Li}_{7} \mathrm{Ti}_{5} \mathrm{O}_{12}$ (111) surface from the electrolyte. The proposed formation of a protective $\alpha-\mathrm{Li}_{2} \mathrm{TiO}_{3}$ layer on cycled $\mathrm{Li}_{4} \mathrm{Ti}_{5} \mathrm{O}_{12}$ is, to the best of our knowledge, yet to be demonstrated on typical polycrystalline $\mathrm{Li}_{x} \mathrm{Ti}_{5} \mathrm{O}_{12}$ particles used in practical lithium-ion batteries. In this situation, energeticallyfavoured $\mathrm{Li}_{7} \mathrm{Ti}_{5} \mathrm{O}_{12}$ (111) surfaces may be exposed to the electrolyte, causing the proposed "zero-bias" mechanism to be realised. To exploit this process in a controlled fashion, for example, by attempting to engineer highly stable SEI layers, both a detailed theoretical understanding of metal oxide surface electrochemistry and experimental characterisation of the formation and subsequent electrochemical performance of zero-bias SEI layers are necessary. We speculate that exploring chemical lithiation or direct synthesis of the relevant lithiumintercalated phase may be rewarding strategies.

More generally, engineering highly reducing metal-oxide surfaces, to form stable SEI layers under zero-bias equilibrium chemistry, is an intriguing and to-date unexplored strategy that requires further exploration through theoretical and experimental studies. We also note that, in concert with this stoichiometry-dependence of reduction drive, it may be possible to further tune the SEI composition, and hence cell performance, by exploiting the different reduction potentials of the varied electrolytes, additives and organic solvents in practical Li-ion batteries. ${ }^{56}$

\section{Summary and conclusions}

We have performed DFT calculations of $\mathrm{Li}_{4} \mathrm{Ti}_{5} \mathrm{O}_{12}, \mathrm{Li}_{7} \mathrm{Ti}_{5} \mathrm{O}_{12}$, and $\alpha-\mathrm{Li}_{2} \mathrm{TiO}_{3}$ surfaces, to identify their preferred structures, compositions, and the thermodynamic reduction drives. For the $\mathrm{Li}_{4} \mathrm{Ti}_{5} \mathrm{O}_{12}$ (111) and $\mathrm{Li}_{7} \mathrm{Ti}_{5} \mathrm{O}_{12}$ (111) surfaces, we have screened more than 600 symmetry inequivalent structures. For both stoichiometries, lithium-terminated surfaces are more stable than titanium-terminated surfaces, which tend to reconstruct. The lowest energy surfaces have surface energies of $0.022 \mathrm{eV} \AA^{-2}$ for $\mathrm{Li}_{4} \mathrm{Ti}_{5} \mathrm{O}_{12}(111)$ and $0.038 \mathrm{eV} \AA^{-2}$ for $\mathrm{Li}_{7} \mathrm{Ti}_{5} \mathrm{O}_{12}$ (111). For $\alpha-\mathrm{Li}_{2} \mathrm{TiO}_{3}$, we have modelled the (100), (110), and (111) surfaces. The (110) and (111) surface energies are high $\left(\sim 0.1 \mathrm{eV} \AA^{-2}\right)$. The (100) $\alpha-\mathrm{Li}_{2} \mathrm{TiO}_{3}$ surface energy is $0.039 \mathrm{eV}$ $\AA^{-2}$, which is comparable to the surface energies of $\mathrm{Li}_{4} \mathrm{Ti}_{5} \mathrm{O}_{12}$ (111) and $\mathrm{Li}_{7} \mathrm{Ti}_{5} \mathrm{O}_{12}$ (111). The high energy (110) and (111) surfaces are therefore predicted to be unstable with respect to reconstruction to facetted (100) surfaces. This is consistent with the surface roughening observed by Kitta et al. that accompanies the formation of the $\alpha-\mathrm{Li}_{2} \mathrm{TiO}_{3}$ surface phase during the first lithium charge/discharge cycle of $\mathrm{Li}_{\{4,7\}} \mathrm{Ti}_{5} \mathrm{O}_{12}$.

Having identified the lowest energy $\mathrm{Li}_{4} \mathrm{Ti}_{5} \mathrm{O}_{12}, \mathrm{Li}_{7} \mathrm{Ti}_{5} \mathrm{O}_{12}$, and $\alpha$ $\mathrm{Li}_{2} \mathrm{TiO}_{3}$ surfaces, we have calculated energies of the highestoccupied Kohn-Sham states, which were aligned to the vacuum energy; $E_{\mathrm{HOS}}^{\mathrm{vac}}$. This measure serves as an approximation to the surface reduction drive in the absence of any external bias, and indicates the propensity for spontaneous electrolyte decomposition upon substrate wetting. For $\mathrm{Li}_{4} \mathrm{Ti}_{5} \mathrm{O}_{12}$ (111) and $\alpha-\mathrm{Li}_{2} \mathrm{TiO}_{3}$ (100), $E_{\mathrm{HOS}}^{\mathrm{vac}}=-5.27$ and $-5.52 \mathrm{eV}$ respectively. For $\mathrm{Li}_{7} \mathrm{Ti}_{5} \mathrm{O}_{12}(111)$, however, $E_{\mathrm{HOS}}^{\mathrm{vac}}=-2.56 \mathrm{eV}$, which is smaller in magnitude than the work function for metallic lithium (2.8 eV (ref. 17 and 18)). 
This indicates an extreme thermodynamic drive for reduction at the pristine $\mathrm{Li}_{7} \mathrm{Ti}_{5} \mathrm{O}_{12}$ (111) surface, which might be exploited to form a thermodynamically stabilised SEI. This suggestion is conceptually related to the results of Hirayama et al., who have shown that the superior electrochemical performance of the $\mathrm{LiMn}_{2} \mathrm{O}_{4}$ (111) surface versus the (110) face is correlated with the formation of a highly stable SEI on electrolyte wetting under "zero bias" thermodynamic equilibrium. ${ }^{19}$ The extreme reduction potential for the pristine $\mathrm{Li}_{7} \mathrm{Ti}_{5} \mathrm{O}_{12}$ (111) surface suggests that this surface will form an SEI under zero-bias equilibrium conditions. An SEI formed in this way may have different, possibly beneficial, properties relative to conventional SEI formation under an applied bias during the first lithium-insertion. More generally, preparing electrode materials with highly reducing surfaces, in order that thermodynamically stable zero-bias SEI layers form when wetted by an electrolyte, is an intriguing, and to-date unexplored, strategy for engineering highly stable electrodes with improved cycle lifetimes.

\section{Acknowledgements}

Support from the EU FP7 program SIRBATT (contract No. 608502) is gratefully acknowledged. B. J. M. acknowledges support from the Royal Society (UF130329), and from EPSRC grant EP/N004302/ 1. J. C. is supported by the MiNECO through a Ramón y Cajal Fellowship and acknowledges support by the Marie Curie Career Integration Grant FP7-PEOPLE-2011-CiG: Project NanoWGS and the Royal Society through the Newton Alumnus scheme. G. T. is supported by EPSRC-UK (EP/I004483/1). Calculations were performed using HPC Wales, N8 (EPSRC EP/K000225/1), the Barcelona Supercomputer Center (BSC, i2BASQUE), and the ARCHER supercomputer through membership of the UK's HPC Materials Chemistry Consortium, which is funded by EPSRC grant EP/L000202, and membership of the UKCP consortium, funded by grant EP/K013564/1. Raw calculation data and analysis scripts for our bulk and stoichiometric surface calculations are deposited at the University of Liverpool repository. ${ }^{57}$

\section{Notes and references}

1 J. Goodenough and K. S. Park, The Li-ion Rechargeable Battery: A Perspective, J. Am. Chem. Soc., 2013, 135, 11671176.

2 X. Sun, P. V. Radovanovic and B. Cui, Advances in Spinel $\mathrm{Li}_{4} \mathrm{Ti}_{5} \mathrm{O}_{12}$ Anode Materials for Lithium-Ion Batteries, New J. Chem., 2014, 39, 38-63.

3 F. Ronci, P. Reale, B. Scrosati, S. Panero, V. Rossi Albertini, P. Perfetti, M. di Michiel and J. M. Merino, HighResolution In Situ Structural Measurements of the $\mathrm{Li}_{4 / 3} \mathrm{Ti}_{5 /}$ ${ }_{3} \mathrm{O}_{4}$ "Zero-Strain" Insertion Material, J. Phys. Chem. B, 2002, 106, 3082-3086.

4 C. Y. Ouyang, Z. Y. Zhong and M. S. Lei, Ab Initio Studies of Structural and Electronic Properties of $\mathrm{Li}_{4} \mathrm{Ti}_{5} \mathrm{O}_{12}$ Spinel, Electrochem. Commun., 2007, 9, 1107-1112.

5 Z. Zhong, C. Ouyang, S. Shi and M. Lei, Ab Initio Studies on $\mathrm{Li}_{4+x} \mathrm{Ti}_{5} \mathrm{O}_{12}$ Compounds as Anode Materials for LithiumIon Batteries, ChemPhysChem, 2008, 9, 2104-2108.
6 P. C. Tsai, W. D. Hsu and S. K. Lin, Atomistic Structure and $A b$ Initio Electrochemical Properties of $\mathrm{Li}_{4} \mathrm{Ti}_{5} \mathrm{O}_{12}$ Defect Spinel for Li Ion Batteries, J. Electrochem. Soc., 2013, 161, A439-A444.

7 X. Lu, et al., Lithium Storage in $\mathrm{Li}_{4} \mathrm{Ti}_{5} \mathrm{O}_{12}$ Spinel: The Full Static Picture from Electron Microscopy, Adv. Mater., 2012, 24, 3233-3238.

8 B. Ziebarth, M. Klinsmann, T. Eckl and C. Elsässer, Lithium Diffusion in the Spinel Phase $\mathrm{Li}_{4} \mathrm{Ti}_{5} \mathrm{O}_{12}$ and in the Rocksalt Phase $\mathrm{Li}_{7} \mathrm{Ti}_{5} \mathrm{O}_{12}$ of Lithium Titanate from First Principles, Phys. Rev. B: Condens. Matter Mater. Phys., 2014, 89, 174301.

9 A notable study of $\mathrm{Li}_{x} \mathrm{Ti}_{5} \mathrm{O}_{12}$ surfaces is that of Ganapathy and Wagemaker, who modelled progressive insertion of $\mathrm{Li}$ at the (100), (110), and (111) $\mathrm{Li}_{4} \mathrm{Ti}_{5} \mathrm{O}_{12}$ surfaces. ${ }^{58}$

10 D. A. Tompsett, S. C. Parker, P. G. Bruce and M. S. Islam, Nanostructuring of $\beta-\mathrm{MnO}_{2}$ : The Important Role of Surface to Bulk Ion Migration, Chem. Mater., 2013, 25, 536-541.

11 M. Kitta, T. Akita, Y. Maeda and M. Kohyama, Study of Surface Reaction of Spinel $\mathrm{Li}_{4} \mathrm{Ti}_{5} \mathrm{O}_{12}$ during the First Lithium Insertion and Extraction Processes Using Atomic Force Microscopy and Analytical Transmission Electron Microscopy, Langmuir, 2012, 28, 12384-12392.

12 D. S. Scholl and J. A. Steckel, DFT Calculations for Surfaces of Solids, in Density Functional Theory: A Practical Introduction, John Wiley \& Sons, Inc., 2009, ch. 4.

13 Y. Gao, Z. Wang and L. Chen, Stability of spinel $\mathrm{Li}_{4} \mathrm{Ti}_{5} \mathrm{O}_{12}$ in air, J. Power Sources, 2014, 245, 684-690.

14 Y. Gao, Z. Wang and L. Chen, Workfunction, a new viewpoint to understand the electrolyte/electrode interface reaction, J. Mater. Chem. A, 2015, 3, 23420-23425.

15 V. Weber, T. Laino, A. Curioni, T. Eckl, C. Engel, J. Kasemchainan and N. Salingue, Computational Study of Lithium Titanate as a Possible Cathode Material for SolidState Lithium-Sulfur Batteries, J. Phys. Chem. C, 2015, 119, 9681-9691.

16 The energy difference between the highest occupied state and the vacuum energy for $\mathrm{Li}_{7} \mathrm{Ti}_{5} \mathrm{O}_{12}$ (111) increases to $\sim 3$ eV for non-stoichiometric Li-excess or deficient surfaces.

17 H. B. Michaelson, The Work Function of the Elements and its Periodicity, J. Appl. Phys., 1977, 48, 4729-4733.

18 S. L. Koch, B. J. Morgan, S. Passerini and G. Teobaldi, Density Functional Theory Screening of Gas-Treatment Strategies for Stabilization of High Energy-Density Lithium Metal Anodes, J. Power Sources, 2015, 296, 150-161.

19 M. Hirayama, H. Ido, K. Kim, W. Cho, K. Tamura, J. Mizuki and R. Kanno, Dynamic Structural Changes at $\mathrm{LiMn}_{2} \mathrm{O}_{4} /$ Electrolyte Interface during Lithium Battery Reaction, $J$. Am. Chem. Soc., 2010, 132, 15268-15276.

20 I. Scivetti and G. Teobaldi, (Sub)Surface-Promoted Disproportionation and Absolute Band Alignment in HighPower $\mathrm{LiMn}_{2} \mathrm{O}_{4}$ Cathodes, J. Phys. Chem. C, 2015, 119, 21358-21368.

21 G. Kresse and J. Furthmüller, Efficient Iterative Schemes for Ab Initio Total-Energy Calculations Using a Plane-Wave Basis Set, Phys. Rev. B: Condens. Matter Mater. Phys., 1996, 54, 11169-11186. 
22 G. Kresse and J. Furthmuller, Efficiency of $A b$ Initio Total Energy Calculations for Metals and Semiconductors using a Plane-Wave Basis Set, Comput. Mater. Sci., 1996, 6, 15-50.

23 P. E. Blöchl, Projector Augmented-Wave Method, Phys. Rev. B: Condens. Matter Mater. Phys., 1994, 50, 17953-17979.

24 G. Kresse and D. Joubert, From Ultrasoft Pseudopotentials to the Projector Augmented-Wave Method, Phys. Rev. B: Condens. Matter Mater. Phys., 1999, 59, 1758-1775.

25 J. P. Perdew, K. Burke and M. Ernzerhof, Generalized Gradient Approximation Made Simple, Phys. Rev. Lett., 1996, 77, 3865-3868.

26 G. Pacchioni, F. Frigoli, D. Ricci and J. A. Weil, Theoretical Description of Hole Localization in a Quartz Al Center: The importance of Exact Electron Exchange, Phys. Rev. B: Condens. Matter Mater. Phys., 2000, 63, 054102.

27 F. Zhou, M. Cococcioni, C. A. Marianetti, D. Morgan and G. Ceder, First-Principles Prediction of Redox Potentials in Transition-Metal Compounds with LDA $+U$, Phys. Rev. B: Condens. Matter Mater. Phys., 2004, 70, 235121.

28 P. Mori-Sánchez, A. J. Cohen and W. Yang, Localization and Delocalization Errors in Density Functional Theory and Implications for Band-Gap Correction, Phys. Rev. Lett., 2008, 100, 146401.

29 J. P. Allen, D. O. Scanlon and G. W. Watson, Electronic Structure of Mixed-Valence Silver Oxide AgO from Hybrid Density-Functional Theory, Phys. Rev. Lett., 2010, 81, 161103.

$30 \mathrm{~J}$. Chen, X. Wu and A. Selloni, Electronic structure and bonding properties of cobalt oxide in the spinel structure, Phys. Rev. B: Condens. Matter Mater. Phys., 2011, 83, 245204.

31 A. C. M. Padilha, J. M. Osorio-Guillén, A. R. Rocha and G. M. Dalpian, $\mathrm{Ti}_{n} \mathrm{O}_{2 n-1}$ Magnéli Phases Studied using Density Functional Theory, Phys. Rev. B: Condens. Matter Mater. Phys., 2014, 90, 035213.

32 B. J. Morgan and G. W. Watson, Intrinsic n-Type Defect Formation in $\mathrm{TiO}_{2}$ : A Comparison of Rutile and Anatase from GGA $+U$ Calculations, J. Phys. Chem. C, 2010, 114, 2321-2328.

33 B. J. Morgan and G. W. Watson, Polaronic Trapping of Electrons and Holes in Anatase $\mathrm{TiO}_{2}$, Phys. Rev. B: Condens. Matter Mater. Phys., 2009, 80, 233102.

34 K. Kataoka, Y. Takahashi, N. Kijima, J. Akimoto and K.-i. Ohshima, Single crystal growth and structure refinement of $\mathrm{Li}_{4} \mathrm{Ti}_{5} \mathrm{O}_{12}$, J. Phys. Chem. Solids, 2008, 69, 1454-1456.

35 M. Kitta, T. Matsuda, Y. Maeda, T. Akita, S. Tanaka, Y. Kido and M. Kohyama, Atomistic structure of a spinel $\mathrm{Li}_{4} \mathrm{Ti}_{5} \mathrm{O}_{12}$ (111) surface elucidated by scanning tunneling microscopy and medium energy ion scattering spectrometry, Surf. Sci., 2014, 619, 5-9.

36 Ziebarth et al. have calculated lithium diffusion barriers between 0.30 and $0.48 \mathrm{eV}$ for $\mathrm{Li}_{4} \mathrm{Ti}_{5} \mathrm{O}_{12}$ and between 0.20 and $0.51 \mathrm{eV}$ for $\mathrm{Li}_{7} \mathrm{Ti}_{5} \mathrm{O}_{12} \cdot{ }^{8}$

37 Q. Zeng, W. Li, J. L. Shi, J. K. Guo, M. W. Zuo and W. J. Wu, A New Microwave Dielectric Ceramic for LTCC Applications, $J$. Am. Ceram. Soc., 2006, 89, 1733-1735.

38 N. Roux, J. Avon, A. Floreancig, J. Mougin, B. Rasneur and S. Ravel, Low-Temperature Tritium Releasing Ceramics as
Potential Materials for the ITER Breeding Blanket, J. Nucl. Mater., 1996, 233, 1431-1435.

39 K. Azuma, C. Dover, D. C. Grinter, R. Grau-Crespo, N. Almora-Barrios, G. Thornton, T. Oda and S. Tanaka, Scanning Tunneling Microscopy and Molecular Dynamics Study of the $\mathrm{Li}_{2} \mathrm{TiO}_{3}$ (001) Surface, J. Phys. Chem. C, 2013, 117, 5126-5131.

40 The VASP input files and optimised geometry for this lowest energy $\alpha-\mathrm{Li}_{2} \mathrm{TiO}_{3}$ structure are available at the NOMAD repository. ${ }^{59}$

41 B. J. Morgan, Two Dimensional Nanosystems, in Computational Modelling of Inorganic Nanomaterials, ed. S. T. Bromley and M. A. Zwijnenberg, CRC Press, 2016, ch. 3.

42 P. W. Tasker, The Stability of Ionic Crystal Surfaces, J. Phys. C: Solid State Phys., 1979, 12, 4977-4984.

43 B. J. Morgan, bsym, DOI: /10.5281/zenodo.57951.

44 D. E. E. Deacon-Smith, D. O. Scanlon, C. R. A. Catlow, A. A. Sokol and S. M. Woodley, Interlayer Cation Exchange Stabilizes Polar Perovskite Surfaces, Adv. Mater., 2014, 26, 7252.

45 Q. Wang, A. R. Oganov, Q. Zhu and X. Zhou, New Reconstructions of the (110) Surface of Rutile $\mathrm{TiO}_{2}$ Predicted by an Evolutionary Method, Phys. Rev. Lett., 2014, 113, 266101.

46 Our calculated surface energies for the lowest energy Dterminated surfaces of both $\mathrm{Li}_{4} \mathrm{Ti}_{5} \mathrm{O}_{12}$ and $\mathrm{Li}_{7} \mathrm{Ti}_{5} \mathrm{O}_{12}$ are $\sim 0.1 \mathrm{eV} \AA^{-2}$, which is comparable to the surface energies reported by Weber et al. ${ }^{15}$

47 G. W. Watson, E. T. Kelsey, N. H. de Leeuw, D. J. Harris and S. C. Parker, Atomistic Simulation of Dislocations, Surfaces and Interfaces in MgO, J. Chem. Soc., Faraday Trans., 1996, 92, 433-438.

$48 \mathrm{~J}$. Neugebauer and M. Scheffler, Adsorbate-Substrate and Adsorbate-Adsorbate Interactions of $\mathrm{Na}$ and $\mathrm{K}$ Adlayers on Al (111), Phys. Rev. B: Condens. Matter Mater. Phys., 1992, 46, 16067-16080.

$49 \mathrm{Gao}$ et al. have recently explored the reduction potential for structurally related $\mathrm{LiTi}_{2} \mathrm{O}_{4}$ (111) surfaces using this technique, with the quantity $E_{\mathrm{HOS}}^{\mathrm{vac}}$ denoted therein as the surface "workfunction". ${ }^{\mathbf{4}}$

50 Verde et al. have recently performed hybrid DFT calculations on $\mathrm{Li}_{4} \mathrm{Ti}_{5} \mathrm{O}_{12}$ and $\mathrm{Li}_{7} \mathrm{Ti}_{5} \mathrm{O}_{12} \cdot{ }^{54}$ They also predicted partially occupied $\mathrm{Ti} d$ states for $\mathrm{Li}_{7} \mathrm{Ti}_{5} \mathrm{O}_{12}$, corresponding to an upward shift of the Fermi energy, and qualitatively agreeing with the description we present here.

51 Our approximate measure of thermodynamic drive for electrolyte reduction provides no information about the kinetics of any such process, which can be expected to depend on factors including the energy alignment of the Fermi energy and electrolyte LUMO, and the spatial overlap of the relevant frontier orbitals.

52 The work function for metallic Li (111) calculated with DFT/ PBE is $2.84 \mathrm{eV}^{\mathbf{1 8}}$

$53 E_{\mathrm{HOS}}^{\mathrm{vac}}$ is sensitive to the exact surface termination, but remains small compared to $\mathrm{Li}_{4} \mathrm{Ti}_{5} \mathrm{O}_{12}$ for lithium excessive and deficient $\mathrm{Li}_{7} \mathrm{Ti}_{5} \mathrm{O}_{12}$ surfaces. For the non- 
stoichiometric surfaces considered in this work $E_{\mathrm{HOS}}^{\mathrm{vac}}=3.13$ $\mathrm{eV}(+2 \mathrm{Li}), 4.22 \mathrm{eV}\left(-2 \mathrm{Li}_{\mathrm{A}}\right)$, and $3.01 \mathrm{eV}\left(-2 \mathrm{Li}_{\mathrm{B}}\right)$.

54 M. G. Verde, L. Baggetto, N. Balke, G. M. Veith, J. K. Seo, Z. Wang and Y. S. Meng, Elucidating the Phase Transformation of $\mathrm{Li}_{4} \mathrm{Ti}_{5} \mathrm{O}_{12}$ Lithiation at the Nanoscale, ACS Nano, 2016, 10, 4312-4321.

55 Y.-B. He, et al., Gassing in $\mathrm{Li}_{4} \mathrm{Ti}_{5} \mathrm{O}_{12}$-based batteries and its remedy, Sci. Rep., 2012, 2, 1-9.

56 S. A. Delp, O. Borodin, M. Olguin, C. G. Eisner, J. L. Allen and T. R. Jow, Importance of Reduction and Oxidation Stability of High Voltage Electrolytes and Additives, Electrochim. Acta, 2016, 209, 498-510.

57 B. J. Morgan, J. Carrasco and G. Teobaldi, Lithium Titanate Spinel Surfaces Dataset, 2016, DOI: 10.17638/ datacat.liverpool.ac.uk/209.

58 S. Ganapathy and M. Wagemaker, Nanosize Storage Properties in Spinel $\mathrm{Li}_{4} \mathrm{Ti}_{5} \mathrm{O}_{12}$ Explained by Anisotropic Surface Lithium Insertion, ACS Nano, 2012, 6, 8702-8712.

59 B. J. Morgan, J. Carrasco and G. Teobaldi, $\alpha$-Li2TiO3 Data Repository [Accessed 2016-01-5]. DOI: /10.17172/NOMAD/ 2016.01.05-1. 